\title{
A importância do Espaço Doméstico Exterior para um modelo de ecodesenvolvimento de cidades médias. $O$ caso do Dondo, Moçambique
}

The Significance of Outdoor Domestic Space to an Ecodevelopment Model of Medium Size Cities. The Case Study of Dondo, Mozambique L'importance de l'espace domestique extérieur pour un modèle d'écodéveloppement de villes moyennes. L'étude de cas de Dondo, Mozambique

\section{Céline Veríssimo}

Tradutor: Isabel Branco

\section{(2) OpenEdition Journals}

Edição electrónica

URL: http://journals.openedition.org/rccs/5277

DOI: $10.4000 /$ rccs. 5277

ISSN: $2182-7435$

Editora

Centro de Estudos Sociais da Universidade de Coimbra

Edição impressa

Data de publição: 1 Maio 2013

Paginação: 177-212

ISSN: 0254-1106

Refêrencia eletrónica

Céline Veríssimo, «A importância do Espaço Doméstico Exterior para um modelo de ecodesenvolvimento de cidades médias. O caso do Dondo, Moçambique », Revista Crítica de Ciências Sociais [Online], 100 | 2013, colocado online no dia 28 outubro 2013, criado a 23 abril 2019. URL : http://journals.openedition.org/rccs/5277 ; DOI : 10.4000/rccs.5277 


\section{CÉLINE VERÍSSIMO}

\section{A importância do Espaço Doméstico Exterior para um modelo de ecodesenvolvimento de cidades médias. $O$ caso do Dondo, Moçambique}

Nos bairros do Dondo, o ambiente urbano materializa-se através da apropriação do ambiente natural pela sociedade, de modo a construir o seu habitat e satisfazer necessidades, de forma duradoura e equilibrada, pois 'a participação humana nos processos da natureza é a condição natural da existência humana'. Para resistir à marginalização da cidade dualística, o espaço exterior em volta da casa - 'Espaço Exterior Doméstico' é adaptado para integrar agricultura e negócios, dando forma a um padrão de crescimento urbano verde e ruralizado. Assumindo que existe uma relação inata entre a humanidade e a natureza, a industrialização e a ascensão do capitalismo marcam a rutura entre 'democracia' e 'ecologia'. Este artigo sugere que é possível as sociedades reafirmarem práticas colaborativas e auto-organizadas.

Palavras-chave: desenvolvimento sustentável; Dondo (Moçambique); ecologia; estratégias de sobrevivência; urbanização.

No Moçambique pré-colonial existiam principalmente dois sistemas sociais opostos: por um lado, as comunidades apátridas Bantu, que desenvolveram um sistema agro-social baseado nas relações de parentesco e na agricultura de subsistência e que viviam em assentamentos dispersos, e por outro lado o estado central Monomotapa, que aumentou a produção agrícola, desenvolveu uma nova tecnologia do metal e expandiu o comércio através de uma rede de cidades muralhadas ligadas à cidade portuária de Sofala. Mais tarde, o colonialismo português introduziu uma economia imperialista através de relações não-sustentáveis de exploração intensiva de recursos humanos e naturais com trabalho forçado e impostos. Isto resultou no aumento da disseminação de pessoas em assentamentos dispersos para escapar à opressão, por um lado, e deu origem a uma forma dualística de urbanização na busca de melhores condições de subsistência, por outro - a "cidade cimento" que é a parte central da cidade pós-colonial constituída por edifícios modernos 
de betão, é rodeada por outra cidade, os "bairros de caniço" moçambicanos do passado, e onde agora vive a maioria da população urbana.

O processo adiado de descolonização do Estado Novo Português coincidiu com a Guerra Fria travada em África. A eleição de Reagan como Presidente em 1980, e em 1979 a de Thatcher como primeira-ministra no Reino Unido, conduziu à sua intensificação com sérias consequências para as antigas colónias portuguesas em África (Guiné-Bissau, Angola e Moçambique). Rapidamente após a independência em 25 de junho de 1975, os EUA e a NATO reforçaram o apartheid na África do Sul para atacar o comunismo em Moçambique (e no Zimbabué), apoiando a guerrilha de oposição da Renamo numa devastadora guerra de desestabilização contra o Marxismo-Leninismo da Frelimo (1977-1992). O modelo de desenvolvimento das "Aldeias Comunais" pós-independência da Frelimo foi uma forma coletiva de organização social baseada no centralismo democrático, influenciado também pelo modernismo, que descurou totalmente quaisquer elementos de auto-organização tradicional. As Cooperativas Agrícolas e as Aldeias Comunais destinavam-se não só à coletivização da sociedade moçambicana livre, como também ao crescimento económico rápido, para resistir à desestabilização estrangeira e consolidar a legitimidade nacional. Sob a constante ameaça dos ataques da Renamo no interior e com o parco apoio do Estado central, houve um êxodo rural em massa em direção às cidades para fugir à guerra e procurar ajuda internacional. Isto assinala o momento de um rápido alargamento urbano pelo país (ver Tabela 1), mas sobretudo desencadeia o reforço das estratégias existentes de auto-organização na transformação urbana para a sobrevivência coletiva.

A herança pré-capitalista da urbanidade doméstica e das culturas agrícolas urbanas ${ }^{1}$ merece reflexão na concetualização do urbanismo de Moçambique como um sistema auto-organizado. Do mesmo modo, o estudo de caso do Dondo 2 é classificado como prova de 'agrocidade'3 em vez de 'aldeia urbana'. A noção de 'agrocidade', como hipótese simultaneamente

\footnotetext{
${ }^{1}$ Ambas as "machambas" coletivas e domésticas existiam nos bairros durante o Estado Monomotapa (AD 1425-1884).

${ }^{2}$ Dondo é a cidade capital do distrito com o mesmo nome na Província de Sofala, na região Central de Moçambique, e está situada na margem Este do Rio Pungué que corre, da Beira para o Oceano Indico, uma distância de cerca de $30 \mathrm{~km}$. O distrito de Dondo tem $2308 \mathrm{~km}^{2}$ de superfície e uma população de 161752 habitantes, distribuídos por duas áreas administrativas chamadas Postos Administrativos: Cidade de Dondo, que foi o Município de Dondo e Chinamacondo e Savane, e Mafambise - que inclui a Sede Mafambisse e Mutua (Administração do Distrito de Dondo, 2006 e INE, 2012)

3 A agenda de desenvolvimento rural socialista da Frelimo foi baseada na 'abordagem agropolitana' de John Friedman (1975) nomeadamente no que toca à edificação de aldeias urbanas em áreas remotas.
} 
positiva e normativa, desafia a atual separação de 'rural' e 'urbano' inerente à cidade dualística de 'cimento' e 'caniço' e caracteriza-se pela pequena dimensão, níveis de baixa densidade, talhões grandes, características construtivas de baixo insumo, habitats naturais e ecossistemas urbanos, permacultura, baixa dependência em recursos básicos naturais periurbanos, grande dependência em recursos naturais básicos urbanos; altos níveis de participação civil no fornecimento urbano de alimentos, autonomia dos agregados familiares relativamente à alimentação das hortas urbanas e rendimentos de negócios domésticos, participação na economia local. Isto produz uma urbanização ecológica e rural espontânea autossustentada pelas próprias comunidades urbanas.

Teorias contemporâneas relacionadas com a sociedade humana e a ecologia começam a incorporar os processos de descentralização e auto-organização (Fuchs, 2000 e 2003; Downton, 2009). Aplicando estes princípios à urbanização dualística em Moçambique, o presente artigo interessa-se pelo facto de que esta sociedade se auto-organiza de um modo que tem as suas origens na resistência ao colonialismo, mas que consiste também numa forma de resistência à noção centralista que o Estado tem de socialismo. Este artigo defende a existência de uma forma alternativa de desenvolvimento que observa as forças auto-organizadas e descentralizadas e demonstra como o 'ecodesenvolvimento' existe não só como uma ideia utópica, mas como uma força real baseada num tipo de auto-organização do habitat humano e na sua relação com a natureza que é aqui caraterizada com base na evidência empírica do estudo de caso.

Cruciais para este argumento são circunstâncias mais recentes que acompanham estes processos. Com a queda do Bloco Soviético e o triunfo do neoliberalismo, pressionado pelo Banco Mundial e pelo Fundo Monetário Internacional em Programas de Ajustamento Estrutural, Moçambique converteu-se à globalização. Do mesmo modo, a 'cidade cimento' é agora o centro do neoliberalismo, como o centro da economia global, onde os doadores estrangeiros e a economia de mercado mundial controlam a política económica nacional, a população e os recursos, exacerbando a premissa de negação da autossuficiência que continua a evoluir gloriosamente à margem. A adoção de um modelo de desenvolvimento neoliberal, que surgiu nos últimos 20 anos, ultrapassa completamente as realidades da sociedade moçambicana. Por isso, o artigo conclui que a estratégia de auto-organização relativa ao agregado familiar/unidade de Espaço Exterior Doméstico, que existiu previamente como estratégia de resistência, em primeiro lugar em relação ao colonialismo e em segundo à definição estadista de socialismo, se tornou uma estratégia de sobrevivência contra uma economia global que 
descuida totalmente a população e a terra. Dado que o modelo capitalista ameaça agora desabar (Brenner et al., 2009; Berberoglu, 2012) estão assim criadas as condições para que aquilo que foi previamente encarado como estratégia de sobrevivência marginal se torne a corrente principal de um novo caminho para o desenvolvimento, através do qual a humanidade se pode salvar a si própria das ruínas do sistema atual.

Por um lado, o caráter explorativo do capitalismo global que, quando funciona bem, é um sistema altamente explorador que subjuga as pessoas e a natureza, exige ser libertado para garantir a sobrevivência. Paradoxalmente, por outro lado, quando o capitalismo se desmorona, as pessoas não estão livres da exploração, enfrentando em vez disso um alto risco de um colapso massivo da subsistência à que se tornou dependente, ou parte integrante, do sistema capitalista deteriorado. À parte das comunidades como o Dondo, ${ }^{4}$ que permaneceram largamente autossuficientes, descentralizadas e próximas da natureza, o falhanço do sistema de capitalismo global deteriora drasticamente os rendimentos familiares e restringe a recuperação rápida necessária para estabelecer um novo estado de ordem dentro de todo o sistema. Isto sugere que os sistemas de organização espontânea em colaboração com a natureza são mais resilientes e autónomos e daí mais imunes aos efeitos da crise externa. Por isso, em configurações particulares sociais descentralizadas nem a pobreza, nem a densificação da população, nem a intensificação da produção são responsáveis pela degradação ambiental e pelo aquecimento global. Como consequência, a expansão urbana, como a produção da espécie humana de habitat, em vez de constituir fonte de problemas ambientais, pobreza e degradação ambiental pode, em vez disso, dar origem ao crescimento de um novo ecodesenvolvimento.

\section{A dialética da divisão crescente entre o habitat humano e a natureza}

Quando a cidade se estabelece com base na acumulação de capital, provoca naturalmente uma divisão entre dois mundos diferentes: a parte da sociedade que se desenvolve através da exploração de pessoas e da natureza e a outra parte, que vive a trabalhar entre si e com a natureza, sendo cada vez mais marginalizada à medida que a parte neoliberal da cidade se expande. Seja um bairro financeiro ou comercial, com o neoliberalismo o centro de

\footnotetext{
${ }^{4}$ Este trabalho é baseado na pesquisa desenvolvida em três bairros - Mafarinha, Nhamayabwe e Thundane, no Município do Dondo (perto da cidade portuária da Beira), Província de Sofala na Região Central de Moçambique. O Município do Dondo tem uma superfície de $382 \mathrm{~km}^{2} \mathrm{e}$ é composto por 10 bairros que contam com 70436 habitantes. A maior parte da população do município habita em construções espontâneas em bairros urbanos, suburbanos e periurbanos em redor da 'cidade cimento' formal.
} 
cada cidade passa a integrar a economia global e perde as ligações à sua própria natureza, espaço e pessoas, nomeadamente à identidade local. Assim, esta polarização extrema crescente entre o lado "formal" e o "informal", o "rico" e o "pobre", "o campo" e "a cidade", criada pela globalização, que marca a diferença entre os poucos que detêm o poder e a grande maioria governada, está na base da relação entre centro e periferia, na qual esta última é sempre profundamente marginalizada.

De acordo com Araújo (1998), esta produção espacial altamente diferenciada em Moçambique resulta de uma relação colonial 'dominador-dominado' que aumentou com a globalização, dadas as complexas relações de complementaridade e oposição que se perpetuaram. Este tipo de crescimento e de padrão de desenvolvimento terá sempre um retorno negativo em áreas adjacentes, acabando por provocar desigualdades vincadas entre as pessoas e a degradação da terra.

Esta divisão entre a sociedade humana e a natureza materializa-se no urbanismo dualístico de Moçambique, que evidencia um sistema centro-periferia, em que a periferia marginalizada constrói de facto um futuro próspero, que neste caso reaproxima a humanidade e natureza. Assim sendo, visto que o centro se vai distanciando cada vez mais da periferia, esta vai construindo a sua própria forma de sobrevivência. Hoje, e com o agravamento de crises, a divisão social e espacial espalha-se e torna-se mais evidente e intensa a nível global. Essas crises remetem para: (a) problemas urbanos (aumento da pobreza urbana, infraestruturas básicas e serviços precários, poluição, etc.); (b) crise ecológica (mudanças climáticas, aquecimento global, extinção da biodiversidade, etc.); (c) desigualdade social (revoltas populares contra a repressão dos Estados autoritários ou baseados na globalização, como a 'Primavera Árabe' e 'Ocupa Wall Street'); e (d) movimentos globais de transição (por exemplo a 'Transition Network'). Por isso, problemas de mudança climática, o pico do petróleo, crise alimentar, políticas económicas de austeridade, diminuição da igualdade social, pobreza mundial, democracias parciais, regimes opressivos também servem para destacar a atual divisão entre humanidade e a terra, que se tem vindo a agravar cada vez mais. A transição para uma sociedade pós-capitalista não envolve necessariamente uma rutura com o atual sistema na forma de revolução, que provavelmente provocaria resultados trágicos. Uma revolução silenciosa não só é possível, como já começou a acontecer, tal como no caso do Dondo. E é assim porque o ecossocialismo constitui, por um lado, uma reação espontânea contra o modo não natural do capitalismo e, por outro, um processo dialético entre grupos sociais e entre sociedade e natureza que redescobre a ligação humana com a natureza (Schultz et al., 2004). 


\section{A urbanização dualística em Moçambique}

A análise histórica mostra que as origens da urbanização em Moçambique estão ligadas a exigências de uma economia mercantil baseada na exportação de materiais, recursos e até pessoas para países estrangeiros (primeiro os árabes, persas, indianos e chineses, e mais tarde os portugueses), que remontam às sociedades pré-coloniais altamente hierarquizadas ${ }^{5}$ descendentes do Grande Reino do Zimbabué, o Monomotapa, e criaram segregação socioespacial. O governo colonial português, caraterizado pela utilização do trabalho forçado e por impostos, levou a população a espalhar-se e a voltar às aldeias familiares dispersas pelas regiões mais remotas (Newit, 1997). Esta dispersão e este isolamento da população moçambicana acontecem como meio de escapar à opressão colonial e encontrar segurança. A segregação espacial e o isolamento também aconteceram entre aldeias e machambas extensas nas regiões rurais (Araújo, 1998), tanto durante a ocupação colonial como nas atuais concessões de terras aos agentes do mercado internacional. Entretanto, os homens moçambicanos, que representavam a principal força de trabalho, estavam estabelecidos em edifícios-dormitório em redor dos locais de trabalho (Casal, 1996; Araújo, 2002). Mais tarde, de 1950 em diante, quando as cidades modernistas portuguesas cresceram, em resultado de um maior afluxo de colonos portugueses para legitimar o Império português de Salazar nas 'Províncias do Ultramar' face à crítica anticolonial internacional do pós-guerra, os trabalhadores portugueses começam gradualmente a estabelecer-se com as suas famílias em assentamentos dispersos em redor das cidades. Como as mulheres não podiam trabalhar, prosseguiam o estilo de vida rural, cultivando hortas em quintais e qualquer espaço aberto disponível dentro e em torno das cidades, para produzir alimentos e complementar aos baixos salários dos homens, especialmente quando o excedente servia para ser comercializado (Guedes, 1976). Perante as crises de fome e a escassez permanente de alimentos, resultante de acontecimentos como desastres naturais e mudanças na política económica, a tradição rural e o conhecimento dos processos naturais foram criativamente adaptados pelas famílias para responder aos desafios urbanos, dando origem aos fenómenos da agricultura urbana, dos mercados alimentares informais e dos negócios domésticos que providenciam comércio e serviços urbanos nas cidades de Moçambique (Costa, 2002).

O crescimento muito rápido dos assentamentos urbanos espontâneos que teve lugar após a independência em 1975 deveu-se sobretudo, e antes mais, à nacionalização da propriedade e da terra, que encorajou as pessoas a ocupar

\footnotetext{
5 O período Monomotapa (AD 200-1884).
} 
TABELA 1 - População de Lourenço Marques durante o Período Colonial e Maputo durante o Período Pós-Independência

\begin{tabular}{cccc}
\hline \multirow{2}{*}{$\begin{array}{c}\text { LOURENÇO MARQUES } \\
\text { (milhares) }\end{array}$} & 1904 & 1935 & 1961 \\
\cline { 2 - 4 } & 10 & 47 & 184 \\
\hline $\begin{array}{c}\text { MAPUTO } \\
\text { (milhões) }\end{array}$ & 1985 & 1990 & $\mathbf{2 0 0 0}$ \\
\cline { 2 - 4 } & 1,09 & 1,59 & 3,14 \\
\hline
\end{tabular}

Fonte: Freund (2007) e UN-HABITAT (2008)

TABELA 2 - População urbana, desenvolvimento e ambiente em Moçambique, comparados com África e regiões desenvolvidas

\begin{tabular}{lccc}
\hline & MOÇAMBIQUE & ÁFRICA & $\begin{array}{c}\text { REGIÕES } \\
\text { DESENVOLVIDAS }\end{array}$ \\
\hline $\begin{array}{l}\text { População urbana como percenta- } \\
\text { gem da população total, 2005 }\end{array}$ & 35 & 38 & 74 \\
\hline $\begin{array}{l}\text { Assentamentos urbanos - percenta- } \\
\text { gem de área total }\end{array}$ & 0.3 & 0.7 & 3.8 \\
\hline $\begin{array}{l}\text { Nível de taxa de crescimento anual } \\
\text { da população urbana }\end{array}$ & 4.8 & 3.4 & 0.6 \\
\hline $\begin{array}{l}\text { Densidade urbana (por km² de exten- } \\
\text { são urbana), 2005 }\end{array}$ & $\mathbf{2 6 0 9}$ & 1589 & 482 \\
\hline $\begin{array}{l}\text { População urbana a viver em bairros } \\
\text { precários, 2005 (\%) }\end{array}$ & $\mathbf{8 0}$ & 51 & - \\
\hline $\begin{array}{l}\text { População urbana com acesso a } \\
\text { melhores instalaçães sanitárias, 2004 } \\
\text { (\%) }\end{array}$ & 53 & 62 & 98 \\
\hline $\begin{array}{l}\text { População urbana com acesso a água } \\
\text { potável, 2004 (\%) }\end{array}$ & $\mathbf{7 2}$ & 84 & 100 \\
\hline $\begin{array}{l}\text { Utilização de energia, 2005 (kg de } \\
\text { petróleo per capita) }\end{array}$ & $\mathbf{4 2 7}$ & 712 & 4937 \\
\hline $\begin{array}{l}\text { Emissão de dióxido de carbono, 2004 } \\
\text { (toneladas métricas per capita) }\end{array}$ & $\mathbf{0 . 1}$ & 1.3 & 536 \\
\hline $\begin{array}{l}\text { Veículos motorizados em utilização, } \\
\text { 2000-2005 (por 1000 habitantes) }\end{array}$ & $\mathbf{8}$ & 31 & \\
\hline
\end{tabular}

Fonte: UN-HABITAT (2008)

as casas recém-abandonadas e os blocos de apartamentos nos arredores coloniais e a ocupar a terra nas áreas suburbanas envolventes, especialmente na cidade capital de Lourenço Marques, atual Maputo. Mais tarde, o êxodo massivo da população rural para as cidades como fuga à guerra de 1976-1992 contra a Renamo contrarrevolucionária também contribuiu (ver Tabela 1). 
Além disso, os efeitos de uma série de catástrofes naturais e de mudanças climáticas, combinadas com o colapso das infraestruturas urbanas e a rápida expansão urbana, aumentaram a segregação socioespacial, que foi exacerbada pela privatização desde 1991. O impacto destes factos levou a um crescente reescalonamento da urbanização dualística herdada, e que caracteriza a paisagem urbana do Moçambique contemporâneo (ver Figura 1). Hoje, a antiga cidade colonial é o centro oficial da cidade, conhecido como a 'cidade de cimento' - devido aos arranha-céus e edifícios de média dimensão, de caráter modernista e europeu, e às estradas pavimentadas, que contrastam com os bairros moçambicanos envolventes, estabelecidos espontaneamente, autoconstruídos e com poucas infraestruturas básicas (ver Figuras 2-4). Em tempos coloniais, estes últimos eram chamados 'caniço' ou 'bairros de caniço', visto este ser na época o único material usado nas construções das casas (Guedes, 1976).

Apesar das transformações socioeconómicas na cidade no pós-independência - atualmente a grande maioria dos residentes na 'cidade de cimento' pertencem à população moçambicana - o contraste entre o urbano (cimento) e o suburbano (caniço) permanece e até se tornou mais definido (Araújo, 1999: 177). Os antigos 'bairros de caniço' são agora simplesmente chamados 'bairros', como qualquer outro bairro formal ou informal, para lhes dar a dignidade que merecem. Os bairros informais são de facto a parte da cidade moçambicana mais dinâmica e mais vibrante e o lugar onde vive a grande maioria da população (ver Tabela 2). Como é evidente nos bairros do Dondo, a área criativa através da qual o sistema urbano se regenera de maneira autónoma reside nas margens populares, mais do que no centro oficial, que se está a tornar em certa medida menos dominante e cada vez mais obsoleto. Em Maputo, tal como em outras capitais africanas, o centro formal domina, espalhando-se sobre os bairros informais e afastando as pessoas para dar lugar a áreas suburbanas que invadem antigas áreas periurbanas (Araújo, 1998 e 1999). O dualismo das cidades moçambicanas é a incarnação espacial da luta entre as relações de classes geradas pelo capitalismo e o sistema social prevalecente, baseado nas relações de parentesco e na proximidade com a terra (Mabojunge, 1984). A génese mercantil da urbanização moçambicana, que tentou reproduzir o modelo europeu e modernista de planeamento urbano, de arquitetura e de modo de vida, especialmente durante o último período da colonização portuguesa, de facto projetou as divisões sociais e as separações na sociedade, e a prática urbana tornou-se a sua base de continuação (Baía, 2011). 
O Espaço Doméstico Exterior e o ecodesenvolvimento de cidades médias | 185

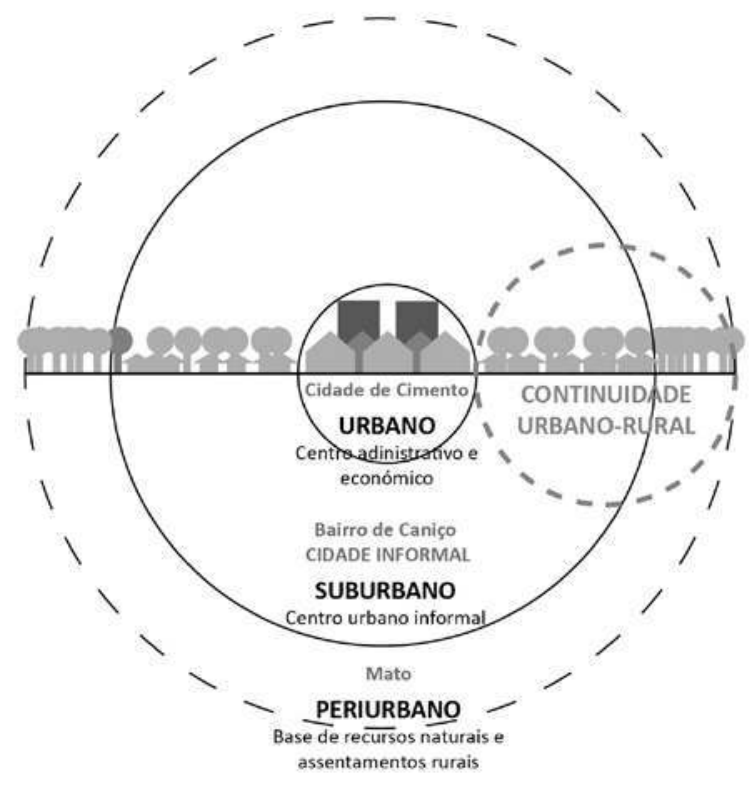

FIGURA 1 - Estrutura urbana dualística da urbanização em Moçambique diagrama esquemático

Fonte: Céline Veríssimo (2009).

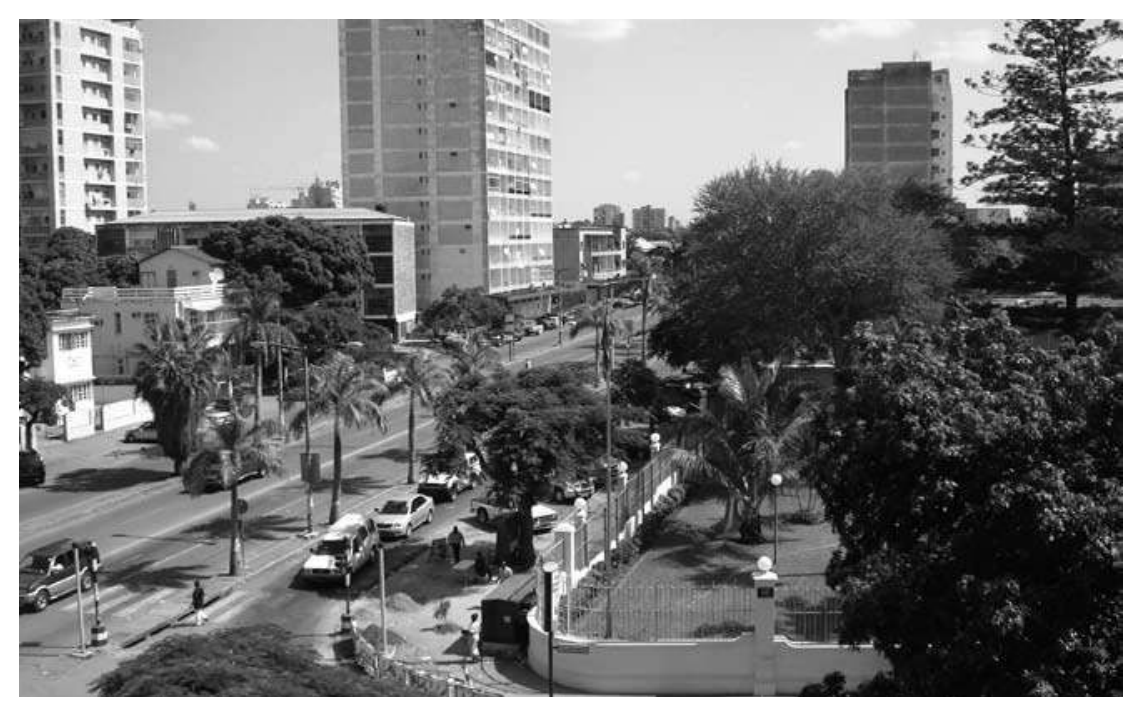

FIGURA 2 - Avenida Julius Nyerere em direção à Avenida Eduardo Mondlane, Maputo

Fonte: Céline Veríssimo (2008). 


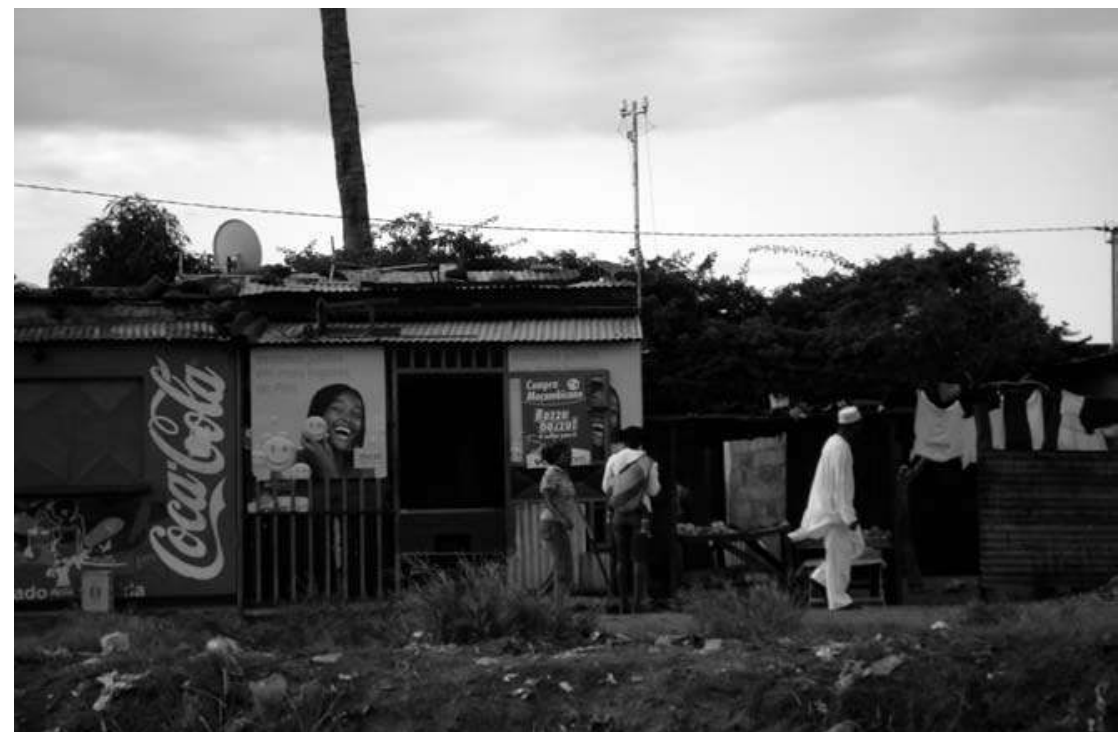

FIGURA 3 - Vista da estrada do Bairro Aeroporto A, Maputo

Fonte: Céline Veríssimo (2008).

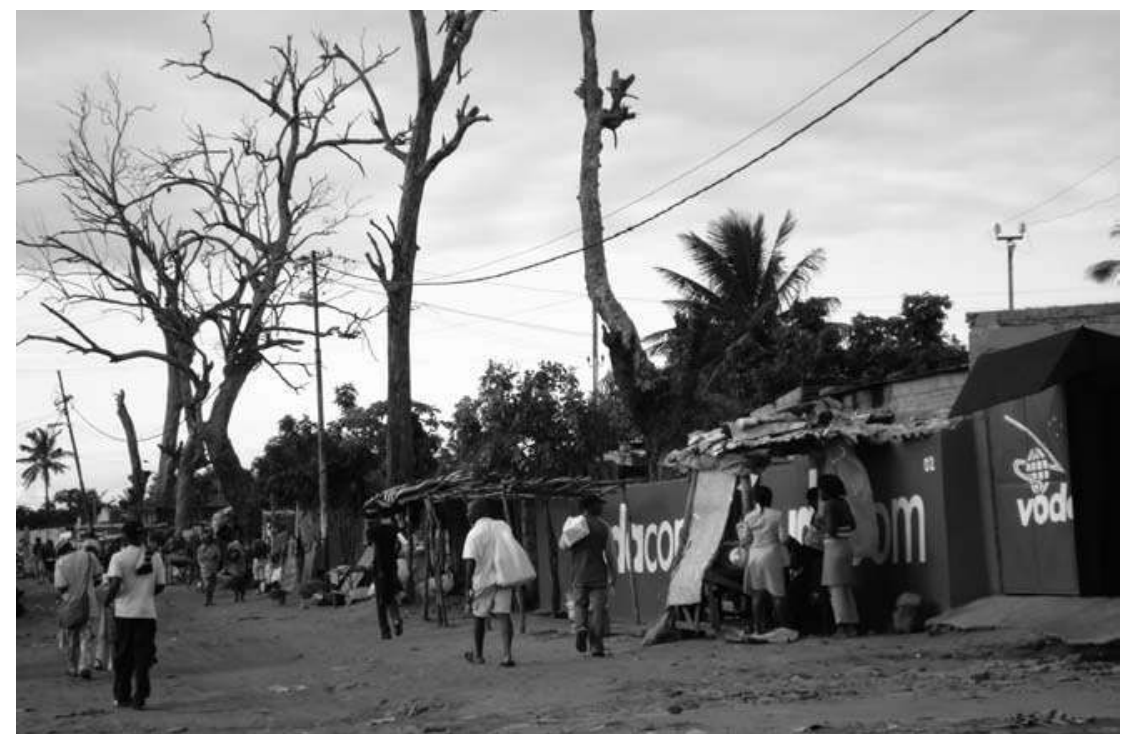

FIGURA 4 - Vida urbana no Bairro Aeroporto A, Maputo

Fonte: Céline Veríssimo (2008). 


\section{Cidades médias}

Apesar de as questões relativas a cidades no mundo em desenvolvimento serem geralmente associadas a megacidades, na verdade a maioria da população urbana mundial vive em pequenas e médias cidades (Hardoy e Satterthwaite, 1986), que se prevê que apresentem as taxas de urbanização mais rápidas do mundo até 2030 (UN-HABITAT, 2012). De acordo com a mesma fonte, espera-se que a população urbana de Moçambique duplique, devido a fatores como o crescimento natural, a migração e a classificação de novas áreas urbanas - passando de 29,1\% em 2000 para 36\% em 2025 (ver Tabelas 3 e 4). A cidade de Maputo permanecerá o único grande centro urbano em Moçambique, com quase 2 milhões de residentes em 2015, e prevê-se que em 2025 duas outras cidades atingirão níveis semelhantes - Beira e Matola, ou Nampula - perfazendo apenas 34\% da população urbana. Por esta razão, em 2020 mais de metade (60\%) da população urbana nacional estará concentrada principalmente em pequenas e médias cidades com menos de 500000 habitantes (ver Tabela 4).

Embora Moçambique seja ainda predominantemente rural e a população nacional urbana constitua apenas 35\% do total (INE, 2007), é agora uma nação urbanizada desde a independência em 1975, por mudanças na política económica e catástrofes naturais. Esta transição de uma população predominante rural para uma cada vez mais urbanizada acontece mais em pequenas e médias cidades do que nas grandes cidades (ver Tabela 5), embora o estudo do fenómeno da urbanização em Moçambique ainda esteja predominantemente focado na região de Maputo. Conhecer o padrão de crescimento urbano de Moçambique em cidades médias é crucial para a compreensão da emergência de um padrão de urbanização semirrural e de baixa densidade que proliferou através do território por uma rede dispersa de municípios, da qual o Dondo, na Província de Sofala, é um exemplo (ver Mapa 1). Além disso, o facto de a grande maioria da população urbana (94\%) viver atualmente em assentamentos informais (UN-HABITAT, 2008) mostra como as conceções convencionais de desenvolvimento urbano têm negligenciado a realidade, bem como importantes relações urbano-rural. Permite igualmente antecipar a emergência de um novo paradigma de urbanização em Moçambique. 


\section{MAPA 1 - Mapa dos limites administrativos do Município do Dondo e bairros selecionados para estudo de casos}

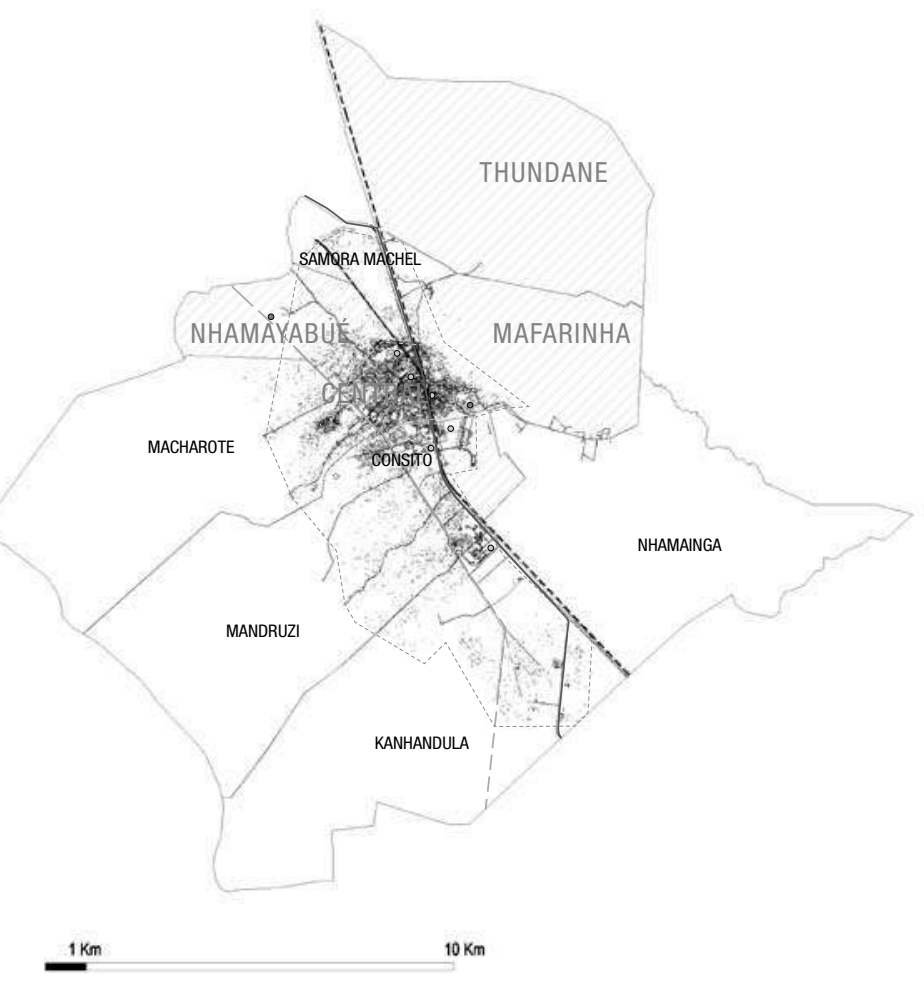

Fonte: Céline Veríssimo, sobre mapa CMD, baseado em trabalho de campo exploratório, 2008.

TABELA 3 - Perfil demográfico de Moçambique, 1950-2025

\begin{tabular}{lcccccccc}
\hline & 1950 & 1960 & 1970 & 1980 & 1990 & 2000 & 2010 & 2025 \\
\hline $\begin{array}{l}\text { População rural } \\
\text { (milhares) }\end{array}$ & 6289 & 7365 & 8902 & 10553 & 10689 & 12905 & 16149 & 20754 \\
\hline $\begin{array}{l}\text { População } \\
\text { urbana } \\
\text { (milhares) }\end{array}$ & 153 & 280 & 546 & 1592 & 2858 & 5296 & 7241 & 11685 \\
$\begin{array}{l}\text { Percentagem } \\
\text { urbana (\%) }\end{array}$ & 2.4 & 3.7 & 5.8 & 13.1 & 21.1 & 29.1 & 31.0 & 36.0 \\
\hline
\end{tabular}

Fonte: UN-HABITAT (2012). 
TABELA 4 - População urbana de Moçambique, número de cidades e percentagem de população urbana

\begin{tabular}{|c|c|c|c|c|c|c|c|c|}
\hline $\begin{array}{l}\text { Classe de dimensão do } \\
\text { assentamento }\end{array}$ & 1950 & 1960 & 1970 & 1980 & 1990 & 2000 & 2010 & 2020 \\
\hline \multicolumn{9}{|c|}{1 para 5 milhões } \\
\hline $\begin{array}{l}\text { Número de } \\
\text { aglomerações }\end{array}$ & 0 & 0 & 0 & 0 & 0 & 1 & 1 & 2 \\
\hline População & 0 & 0 & 0 & 0 & 0 & 1019 & 1132 & 2636 \\
\hline $\begin{array}{l}\text { Percentagem de } \\
\text { população urbana }\end{array}$ & 0 & 0 & 0 & 0 & 0 & 19 & 16 & 27 \\
\hline \multicolumn{9}{|c|}{500000 para 1 milhão } \\
\hline $\begin{array}{l}\text { Número de } \\
\text { aglomerações }\end{array}$ & 0 & 0 & 0 & 1 & 1 & 0 & 2 & 2 \\
\hline População & 0 & 0 & 0 & 550 & 776 & 0 & 1289 & 1365 \\
\hline $\begin{array}{l}\text { Percentagem de } \\
\text { população urbana }\end{array}$ & 0 & 0 & 0 & 35 & 27 & 0 & 18 & 14 \\
\hline \multicolumn{9}{|c|}{ Menos de 500000} \\
\hline População & 153 & 280 & 546 & 1041 & 2082 & 4277 & 4820 & 5907 \\
\hline $\begin{array}{l}\text { Percentagem de } \\
\text { população urbana }\end{array}$ & 100 & 100 & 100 & 65 & 73 & 81 & 67 & 60 \\
\hline
\end{tabular}

Fonte: UN-HABITAT (2012).

TABELA 5 - Estimativas de população por área de residência, 1997 e 2007

\begin{tabular}{lcccc}
\hline & 1997 (hab.) & 2007 (hab.) & $\begin{array}{c}\text { CRESCIMENTO } \\
\text { ABSOLUTO } \\
\text { (hab.) }\end{array}$ & $\begin{array}{c}\text { TAXA ANUAL DE } \\
\text { CRESCIMENTO } \\
\text { (\%) }\end{array}$ \\
\hline NACIONAL & 16075708 & 20530714 & 4455006 & 2,48 \\
\hline URBANO & 4601100 & 6203035 & 1601935 & 3,03 \\
\hline RURAL & 11474608 & 14327679 & 2853071 & 2,25 \\
\hline DISTRITO DE DONDO & 117719 & 142387 & 24668 & 2,14 \\
\hline MUNICÍPIO DE DONDO & 62424 & 70436 & 8012 & 1,35 \\
\hline TODOS OS MUNICÍPIOS & 4052274 & 5361819 & 1309545 & 2,84 \\
\hline CIDADE DE MAPUTO & 966000 & 1068607 & 102607 & 1,01 \\
\hline CIDADE DA BEIRA & 405040 & 418141 & 13101 & 0,32 \\
\hline
\end{tabular}

Fonte: INE (2007). 


\section{Degradação da terra, problemas ambientais e mudança climática}

Assume-se geralmente que as principais fontes de impactos ambientais sobre as cidades no mundo em desenvolvimento estão relacionadas com o desenvolvimento urbano e industrial. Estes impactos consistem em primeiro lugar na deflorestação, erosão dos solos e poluição, que provocam problemas ambientais tais como doenças e riscos físicos que afetam o bem-estar humano e dos ecossistemas naturais (ver Tabela 6). Confrontadas com a degradação ambiental progressiva da sua base de recursos nas áreas rurais, as pessoas são atraídas pelas ideias de progresso, emprego e a oportunidade de ganhar um ordenado que as cidades oferecem. Uma vez na cidade, o desemprego elevado e a escassez de trabalho assalariado obrigam-nas a ajustarem-se aos desafios urbanos fazendo uso dos seus conhecimentos rurais e reinventando formas tradicionais de produção de maneira a poderem reproduzir as condições ambientais naturais que tão bem conhecem e de que sempre dependeram. Através de estratégias simples mas simultaneamente sofisticadas, as pessoas não se limitam a adaptar as suas vidas ao cenário desafiante que encontraram nas cidades, mas estão de facto a reconstituir o ambiente natural como parte do seu habitat físico e como uma precondição natural de vida.

Apesar dos esforços das autoridades locais, as infraestruturas continuam a ser inadequadas, pela sua capacidade muito limitada e sobrecarga de responsabilidades. No entanto, a municipalidade do Dondo implementou um novo sistema de orçamento e de planeamento participativo, ${ }^{6}$ que gradualmente melhorou e alargou a distribuição de infraestruturas básicas e serviços pelos bairros do Dondo. Contudo, a libertação desregulada dos resíduos industriais dentro de bairros, o número insuficiente de latrinas modernas, a utilização contínua de poços e o uso de remédios de curandeiros para os problemas de saúde ainda facilitam a disseminação de doenças contraídas através do ar e da água (Administração do Dondo, 2006). Além destes aspetos, as mudanças climáticas conduziram a um agravamento das secas sazonais, ondas de calor e perda de colheitas, alternando com cheias sazonais em novas zonas criadas pela erosão do solo (IPCC, 2007). Se por um lado tudo isto tem aumentado a vulnerabilidade das populações às crises político-económicas e ambientais, por outro lado é um facto que aciona estratégias de organização da comunidade mais inovadoras e de maior resiliência.

\footnotetext{
${ }^{6}$ O processo da orçamentação participativa do Município do Dondo foi implementado em Moçambique em 1996 por Hemma Tengler e Carlos Roque, da Cooperação da Áustria.
} 
TABELA 6 - Problemas ambientais nos bairros informais do Dondo

\begin{tabular}{|c|c|c|c|c|}
\hline \multirow{2}{*}{\multicolumn{2}{|c|}{$\begin{array}{l}\text { PROBLEMAS } \\
\text { AMBIENTAIS }\end{array}$}} & \multirow{2}{*}{$\begin{array}{l}\text { CAUSAS DOS } \\
\text { PROBLEMAS }\end{array}$} & \multirow{2}{*}{$\begin{array}{l}\text { EFEITOS NAS } \\
\text { PESSOAS }\end{array}$} & \multirow{2}{*}{$\begin{array}{l}\text { EFEITOS NA } \\
\text { NATUREZA }\end{array}$} \\
\hline & & & & \\
\hline & $\begin{array}{l}\text { Deficiente gestão } \\
\text { de recolha de lixo } \\
\text { e de resíduos; } \\
\text {. Fornecimento } \\
\text { insuficiente de água } \\
\text { potável; } \\
\text {. Contaminação de } \\
\text { água; } \\
\text {. Deficientes } \\
\text { condições na } \\
\text { habitação por falta } \\
\text { de manutenção; } \\
\text { Crime facilitado pela } \\
\text { falta de iluminação } \\
\text { pública e segurança } \\
\text { das casas; } \\
\text { Cheias sazonais; } \\
\text {. Erosão do solo } \\
\text { urbano; } \\
\text { VALE MANDRUZl: } \\
\text {. Cheias sazonais e } \\
\text { secas; } \\
\text {. Degradação dos } \\
\text { mangais; } \\
\text { THUNDANE: } \\
\text {. Desflorestação } \\
\text { frequente } \\
\text { indiscriminada; } \\
\text { - Acessos deficientes } \\
\text { (solo pantanoso); } \\
\text { Incêndios } \\
\text { frequentes e } \\
\text { descontrolados; animais } \\
\text { selvagens com } \\
\text { utilização de armas } \\
\text { tradicionais. } \\
\text { agricultura nómada } \\
\text { tradicional; } \\
\text { Cadores furtivos } \\
\text { de }\end{array}$ & $\begin{array}{l}\text { Recursos humanos } \\
\text { e financeiros } \\
\text { insuficientes } \\
\text { para fornecer as } \\
\text { infraestruturas } \\
\text { básicas e gestão } \\
\text { urbana necessárias; } \\
\text { Desperdício } \\
\text { descontrolado } \\
\text { e sem gestão } \\
\text { ambiental do setor } \\
\text { industrial dentro de } \\
\text { áreas residenciais; } \\
\text { Setores de negócio } \\
\text { da indústria } \\
\text { de madeira e } \\
\text { florestal grandes e } \\
\text { descontrolados; } \\
\text { Necessidade } \\
\text { contínua de lenha } \\
\text { e carvão como } \\
\text { combustível } \\
\text { doméstico principal; } \\
\text { Uso tradicional } \\
\text { da madeira como } \\
\text { material principal } \\
\text { estrutural das casas; } \\
\text { Gestão precária } \\
\text { e recursos } \\
\text { insuficientes do } \\
\text { ambiente natural; } \\
\text { Alguns hábitos } \\
\text { culturais } \\
\text { inapropriados que } \\
\text { afetam a gestão dos } \\
\text { recursos naturais. }\end{array}$ & $\begin{array}{l}\text { HIV/SIDA, malária, } \\
\text { diarreia e disenteria; } \\
\text { Falta de } \\
\text { combustível; } \\
\text { Escassez de fontes } \\
\text { de materiais } \\
\text { de construção } \\
\text { tradicionais; } \\
\text { Cheias sazonais em } \\
\text { novas áreas com } \\
\text { tendência para } \\
\text { inundações; } \\
\text { Erosão do solo } \\
\text { (perda de vidas, } \\
\text { casas, estradas e } \\
\text { áreas agrícolas); } \\
\text { Poluição de rios e } \\
\text { águas submarinas; } \\
\text { Perda de colheitas; } \\
\text { Pobreza e fome; } \\
\text { Maiores consumos } \\
\text { de energia e de } \\
\text { tempo na busca } \\
\text { de lenha, carvão e } \\
\text { madeira; } \\
\text { Capacidade e } \\
\text { potencial limitados } \\
\text { para participação } \\
\text { no desenvolvimento } \\
\text { económico. }\end{array}$ & $\begin{array}{l}\text { Desflorestação; } \\
\text { Desertificação; } \\
\text { Perda de vida } \\
\text { selvagem e de } \\
\text { biodiversidade; } \\
\text { Diminuição dos } \\
\text { recursos naturais; } \\
\text { Poluição do ar, água } \\
\text { e solo; } \\
\text { Mudança climática; } \\
\text { Limitação na } \\
\text { capacidade } \\
\text { regeneradora dos } \\
\text { ciclos de vida da } \\
\text { natureza. }\end{array}$ \\
\hline
\end{tabular}

Fonte: Baseado em Administração do Dondo (2006) e na observação e nos dados primários recolhidos durante o trabalho de campo. 


\section{Transformação da unidade de habitação tradicional, reorganização das estratégias de sustento e a agrocidade emergente}

Enfrentando a degradação da sua base de recursos naturais, problemas ambientais e desemprego, as famílias transformaram a utilização do espaço doméstico e reorganizaram estratégias de produção para assegurar o seu sustento. O espaço exterior que tradicionalmente inclui a casa e tem funções sociais e domésticas, a que chamei 'Espaço Exterior Doméstico' (EED), torna-se estrategicamente ecológico e produtivo em termos de alimento, salário, sombra, ar fresco e puro e convívio social (ver Figuras 5-10), não só para facilitar a adaptação em relação a problemas ambientais, degradação de recursos, mudanças climáticas e transformação de políticas económicas, mas em particular para reproduzir as condições naturais necessárias que assegurem o sustento tradicionalmente ligado à natureza - "as estratégias de subsistência são organizadas e desenvolvidas pelas famílias de maneira a permitir-lhes encarar a adversidade económica sem perderem a coesão e identidade familiar" (Costa, 2002: 267). Durante décadas, mulheres de várias origens e lugares cultivaram hortas urbanas, conhecidas localmente como machambas, ${ }^{7}$ também no EED ou em qualquer outro espaço disponível nas cidades de Moçambique (Sheldon, 1999). Apesar do facto de a maior produção alimentar provir das machambas rurais - a média nacional de terra cultivada por família é de 1,66 hectares (ver Tabela 7) - resultados obtidos durante o trabalho de campo demonstram que as famílias urbanas nos bairros do Dondo dependem das machambas urbanas no EED, sendo assim uma importante fonte complementar de alimentos e frutos (ver Tabela 8). As machambas urbanas observadas em espaços abertos pelos bairros do Dondo, são cultivadas por famílias que têm um pequeno EED (Veríssimo, 2010). Como resposta à escassez e à adversidade, isto garante que o conhecimento próximo do sistema ecológico se prolonga de forma ininterrupta. O processo de transformação deste espaço baseia-se na continuação e reinvenção de formas de subsistência familiar e não numa rutura assumida com o seu passado cultural, e evolui através da tipologia tradicional da casa moçambicana e da noção coletiva de 'casa' - o muti.

\footnotetext{
${ }_{7}$ Cultivo familiar para o consumo de alimentação própria, mas também para venda pontual em mercados. No Município do Dondo, a maioria dos residentes cultiva machambas domésticas como jardins de policultura no talhão das suas casas no interior da cidade e em redor do talhão da casa nas áreas rurais. As machambas maiores estão situadas não muito longe no fértil do vale do Rio Pungué ou mais dispersamente no interior das terras em direção a Thundane. As machambas são não uma fonte essencial de alimentos apenas para os pobres, mas também para os assalariados.
} 
TABELA 7 - Terra de cultivo familiar (Machamba) - Perfil por Província, 1996-2002

\begin{tabular}{|c|c|c|c|c|c|c|c|c|c|c|c|}
\hline Província & \multicolumn{4}{|c|}{ Norte } & \multicolumn{3}{|c|}{ Centro } & \multicolumn{3}{|c|}{ Sul } & \multirow[b]{2}{*}{$\begin{array}{l}\bar{\pi} \\
\overline{0} \\
\overline{\tilde{J}} \\
z\end{array}$} \\
\hline $\begin{array}{l}\text { Machamba } \\
\text { Perfil }\end{array}$ & 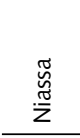 & $\begin{array}{l}\frac{0}{0} \\
\frac{00}{00} \\
\frac{0}{0} \\
u\end{array}$ & $\begin{array}{l}\frac{\pi}{\bar{J}} \\
\frac{0}{E} \\
\frac{\pi}{z}\end{array}$ & $\begin{array}{l}\frac{\pi}{N} \\
\text { N } \\
\text { E్ } \\
\text { N } \\
\end{array}$ & 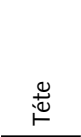 & 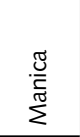 & $\begin{array}{l}\frac{\pi}{\pi} \\
\frac{\pi}{0} \\
\end{array}$ & 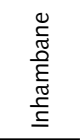 & $\begin{array}{l}\mathbb{N} \\
\mathbb{N}\end{array}$ & 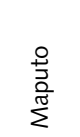 & \\
\hline \multicolumn{12}{|l|}{$\begin{array}{l}\text { Área total } \\
\text { (média/ha) }\end{array}$} \\
\hline 1996 & 1.61 & 1.37 & 1.40 & 0.98 & 1.60 & 1.83 & 1.87 & 2.31 & 2.03 & 1.60 & 1.51 \\
\hline 2002 & 1.65 & 1.37 & 1.56 & 1.25 & 2.35 & 1.92 & 2.06 & 1.86 & 2.12 & 1.77 & 1.66 \\
\hline \multicolumn{12}{|c|}{$\begin{array}{l}\text { Área cultivada } \\
\text { (média/ha) }\end{array}$} \\
\hline 1996 & 1.28 & 1.10 & 1.22 & 0.88 & 1.25 & 1.41 & 1.33 & 1.96 & 1.75 & 1.28 & 1.26 \\
\hline 2002 & 1.51 & 1.26 & 1.06 & 1.14 & 2.13 & 1.50 & 1.72 & 1.27 & 1.51 & 1.16 & 1.34 \\
\hline \multicolumn{12}{|l|}{$\begin{array}{l}\text { Área total / } \\
\text { adulto } \\
\text { (média/ha) }\end{array}$} \\
\hline 1996 & 0.45 & 0.45 & 0.43 & 0.28 & 0.41 & 0.42 & 0.45 & 0.63 & 0.42 & 0.37 & 0.42 \\
\hline 2002 & 0.47 & 0.45 & 0.54 & 0.40 & 0.69 & 0.48 & 0.55 & 0.53 & 0.60 & 0.50 & 0.50 \\
\hline \multicolumn{12}{|c|}{$\begin{array}{l}\text { Área cultivada/ } \\
\text { adulto } \\
\text { (média/ha) } \\
\end{array}$} \\
\hline 1996 & 0.35 & 0.36 & 0.38 & 0.25 & 0.33 & 0.32 & 0.33 & 0.54 & 0.37 & 0.29 & 0.35 \\
\hline 2002 & 0.43 & 0.41 & 0.36 & 0.36 & 0.62 & 0.38 & 0.42 & 0.36 & 0.41 & 0.33 & 0.40 \\
\hline \multicolumn{12}{|c|}{$\begin{array}{l}\text { Tração animal } \\
(\%)\end{array}$} \\
\hline 1996 & 0 & 0 & 0 & 0 & 2 & 9 & 1 & 30 & 37 & 19 & 7 \\
\hline 2002 & 0 & 0 & 0 & 0 & 35 & 11 & 2 & 47 & 44 & 12 & 11 \\
\hline \multicolumn{12}{|c|}{$\begin{array}{l}\text { Fertilizantes } \\
\text { químicos }(\%)\end{array}$} \\
\hline 1996 & 6 & 1 & 3 & 0 & 0 & 0 & 0 & 0 & 2 & 0 & 1 \\
\hline 2002 & 7 & 3 & 3 & 1 & 15 & 3 & 1 & 2 & 5 & 3 & 4 \\
\hline \multicolumn{12}{|l|}{ Estrume (\%) } \\
\hline 1996 & 1 & 0 & 2 & 8 & 1 & 4 & 1 & 6 & 2 & 2 & 3 \\
\hline 2002 & 4 & 1 & 1 & 1 & 14 & 9 & 2 & 24 & 12 & 15 & 6 \\
\hline \multicolumn{12}{|c|}{ Irrigação (\%) } \\
\hline 1996 & 2 & 1 & 4 & 1 & 0 & 8 & 3 & 8 & 23 & 4 & 4 \\
\hline 2002 & 8 & 3 & 2 & 1 & 28 & 22 & 6 & 29 & 27 & 24 & 11 \\
\hline
\end{tabular}


cont.

\begin{tabular}{|c|c|c|c|c|c|c|c|c|c|c|c|}
\hline Província & \multicolumn{4}{|c|}{ Norte } & \multicolumn{3}{|c|}{ Centro } & \multicolumn{3}{|c|}{ Sul } & \multirow[b]{2}{*}{$\begin{array}{l}\bar{\sigma} \\
\overline{\tilde{o}} \\
\overline{\tilde{g}} \\
\bar{z}\end{array}$} \\
\hline $\begin{array}{l}\text { Machamba } \\
\text { Perfil }\end{array}$ & $\begin{array}{l}\underset{\widetilde{W}}{\tilde{W}} \\
\stackrel{\tilde{\pi}}{Z}\end{array}$ & $\begin{array}{l}\frac{0}{0} \\
\frac{0}{00} \\
\frac{0}{0} \\
0 \\
ن\end{array}$ & $\begin{array}{l}\frac{\pi}{0} \\
\frac{0}{\tilde{E}} \\
\frac{\pi}{2}\end{array}$ & $\begin{array}{l}\frac{\pi}{N} \\
\mathbb{N} \\
\frac{N}{N} \\
N\end{array}$ & 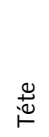 & $\frac{\sqrt[J]{J}}{\sum_{\pi}^{\pi}}$ & $\begin{array}{l}\frac{\pi}{\pi} \\
\frac{\pi}{0} \\
n\end{array}$ & 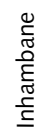 & $\begin{array}{l}\mathbb{N} \\
\mathbb{N}\end{array}$ & 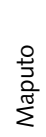 & \\
\hline \multicolumn{12}{|c|}{$\begin{array}{l}\text { Trabalho } \\
\text { contratado (\%) }\end{array}$} \\
\hline 1996 & 17 & 17 & 25 & 17 & 16 & 20 & 17 & 14 & 26 & 14 & 19 \\
\hline 2002 & 21 & 22 & 5 & 13 & 31 & 28 & 18 & 19 & 14 & 21 & 16 \\
\hline \multicolumn{12}{|c|}{$\begin{array}{l}\text { Possui bicicleta } \\
(\%)\end{array}$} \\
\hline 1996 & 17 & 7 & 9 & 7 & 8 & 3 & 4 & 3 & 3 & 1 & 7 \\
\hline 2002 & 42 & 20 & 14 & 38 & 36 & 17 & 20 & 4 & 10 & 9 & 23 \\
\hline \multicolumn{12}{|c|}{$\begin{array}{l}\text { Proprietário de } \\
\text { qualquer } \\
\text { animal (\%) }\end{array}$} \\
\hline 1996 & 67 & 49 & 76 & 73 & 80 & 79 & 88 & 89 & 75 & 70 & 74 \\
\hline 2002 & 62 & 66 & 72 & 78 & 85 & 85 & 79 & 84 & 76 & 74 & 76 \\
\hline \multicolumn{12}{|c|}{$\begin{array}{l}\text { Proprietário de } \\
\text { gado (\%) } \\
\end{array}$} \\
\hline 1996 & 0 & 1 & 0 & 0 & 8 & 9 & 3 & 10 & 16 & 5 & 3 \\
\hline 2002 & 0 & 0 & 1 & 0 & 14 & 8 & 1 & 8 & 18 & 5 & 4 \\
\hline \multicolumn{12}{|c|}{$\begin{array}{l}\text { Proprietário de } \\
\text { cabras/ } \\
\text { ovelhas (\%) } \\
\end{array}$} \\
\hline 1996 & 16 & 16 & 11 & 5 & 34 & 35 & 35 & 38 & 41 & 21 & 20 \\
\hline 2002 & 15 & 23 & 22 & 11 & 52 & 48 & 42 & 41 & 30 & 27 & 27 \\
\hline \multicolumn{12}{|c|}{$\begin{array}{l}\text { Proprietário de } \\
\text { porcos (\%) } \\
\end{array}$} \\
\hline 1996 & 4 & 6 & 15 & 11 & 19 & 12 & 17 & 47 & 20 & 4 & 16 \\
\hline 2002 & 1 & 9 & 10 & 16 & 18 & 15 & 12 & 45 & 18 & 11 & 15 \\
\hline \multicolumn{12}{|c|}{$\begin{array}{l}\text { Proprietário de } \\
\text { aves (\%) }\end{array}$} \\
\hline 1996 & 11 & 13 & 22 & 20 & 17 & 18 & 26 & 23 & 29 & 30 & 21 \\
\hline 2002 & 10 & 11 & 11 & 10 & 10 & 16 & 18 & 23 & 26 & 40 & 14 \\
\hline
\end{tabular}

Fonte: Adaptado de Boughton et al. (2006: 48). 
No muti, a vida decorre mais no exterior do que no interior das casas e revela uma fortíssima 'urbanidade doméstica' que é a base da atual organização comunitária descentralizada dos bairros desenvolvidos através do EED. De acordo com Costa, os aspetos multidimensionais da mudança urbana só podem ser entendidos considerando a produção do espaço doméstico, a que Costa chama 'espaço do lar', porque molda as cidades africanas através das suas práticas sociais e espaciais (Costa, 2011). Tendo ainda em conta que a oferta de serviços é muito limitada, de tudo isto resulta que a manutenção do ambiente urbano é gerida coletivamente e as infraestruturas e os serviços improvisados pelas comunidades, numa forma espontânea de ajudar a manter o equilíbrio do sistema urbano. A maior parte das famílias urbanas depende de atividades informais improvisadas no seu EED (ver Tabelas 8 e 9): hortas domésticas para subsistência e rendimento, quando o excedente o permite, com bancas e mercearias improvisadas para venda de bens essenciais, vegetais, fruta, bem como oferta dos serviços típicos disponibilizados pela cidade (carpinteiro, barbeiro, alfaiate, mecânico, etc.)(ver Tabela 10). O EED molda, assim, um novo tipo ruralizado de bairros urbanos em cidades de média dimensão, às quais chamei agrocidade.

TABELA 8 - Nível de dependência do espaço exterior doméstico para o sustento das famílias: segurança alimentar e rendimento

\begin{tabular}{lcccccccc}
\hline \multirow{2}{*}{ BAIRRO } & $\begin{array}{c}\text { Fonte exclusiva } \\
\text { (única) } \\
\text { de... }\end{array}$ & $\begin{array}{c}\text { Fonte } \\
\text { complementar } \\
\text { (significativa) } \\
\text { de... }\end{array}$ & $\begin{array}{c}\text { Fonte suplementar } \\
\text { (apoio) } \\
\text { de... }\end{array}$ & $\begin{array}{c}\text { Apenas como } \\
\text { fonte de frutos e } \\
\text { não como fonte de } \\
\text { rendimento }\end{array}$ \\
\cline { 2 - 9 } & ALIM. & RENDIM. & ALIM. & RENDIM. & ALIM. & RENDIM & ALIM. & RENDIM. \\
\hline $\begin{array}{l}\text { NHAMAYABUÉ: } \\
32 \text { famílias }\end{array}$ & - & 26 & 12 & 3 & 12 & - & 7 & - \\
\hline $\begin{array}{l}\text { MAFARINHA: } \\
25 \text { famílias }\end{array}$ & - & 19 & 8 & 4 & 6 & - & 11 & 1 \\
\hline $\begin{array}{l}\text { THUNDANE: } \\
3 \text { famílias }\end{array}$ & 1 & - & 2 & 3 & - & - & - & - \\
\hline $\begin{array}{l}\text { TOTAL: } \\
60 \text { famílias }\end{array}$ & 1 & 45 & 22 & 10 & 18 & - & 18 & 1 \\
\hline
\end{tabular}

Fonte: Céline Veríssimo (2011). 
TABELA 9 - Tamanho médio das áreas multifuncionais do espaço exterior doméstico

\begin{tabular}{|c|c|c|c|c|c|c|c|c|}
\hline \multirow[b]{3}{*}{$\begin{array}{l}\text { O } \\
\frac{\alpha}{\alpha} \\
\frac{\alpha}{\sigma}\end{array}$} & \multirow[b]{3}{*}{ 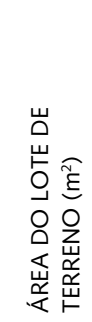 } & \multirow[b]{3}{*}{ 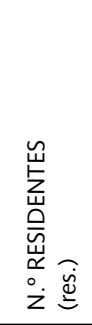 } & \multirow{3}{*}{ 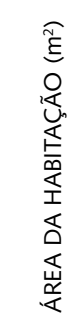 } & \multirow[b]{3}{*}{ 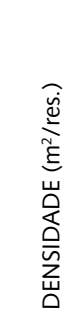 } & \multicolumn{4}{|c|}{ ESPAÇO EXTERIOR DOMÉSTICO } \\
\hline & & & & & \multirow[b]{2}{*}{ 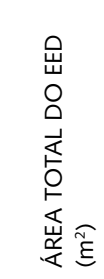 } & \multirow[b]{2}{*}{ 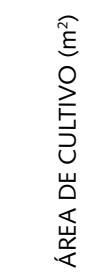 } & \multicolumn{2}{|c|}{ NEGÓCIO } \\
\hline & & & & & & & 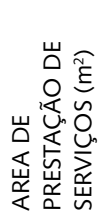 & 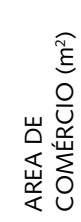 \\
\hline NHANMAYABUÉ & 531 & 6 & 53 & 9 & 478 & 122 & 21 & 14 \\
\hline MAFARINHA & 402 & 5 & 38 & 8,60 & 363 & 128 & 7 & 4 \\
\hline THUNDANE & 3967 & 7 & 42 & 6 & 3924 & 3085 & 0 & 1 \\
\hline TOTAL & 1633 & 6 & 44 & 8 & 1588 & 1112 & 9 & 6 \\
\hline
\end{tabular}

Fonte: Céline Veríssimo (2011).

TABELA 10 - Síntese dos entrevistados principais

(por unidade comunal, quarteirão, género e ocupação profissional por bairro) acerca da produção no Espaço Exterior Doméstico

\begin{tabular}{|c|c|c|c|c|c|c|c|c|}
\hline \multirow[b]{2}{*}{$\begin{array}{l}\text { BAIRROS ESTUDO } \\
\text { DE CASO }\end{array}$} & \multicolumn{2}{|c|}{ LOCALIZAÇÃO } & \multirow{2}{*}{$\begin{array}{c}\text { ESPAÇO } \\
\text { EXTERIOR } \\
\text { DOMÉSTICO } \\
\text { - EED }\end{array}$} & \multicolumn{2}{|c|}{ ENTREVISTAS } & \multicolumn{3}{|c|}{ PRODUÇÃO NOS EED } \\
\hline & : & 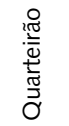 & & 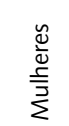 & 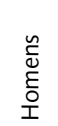 & 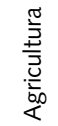 & : & 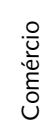 \\
\hline $\begin{array}{l}\text { B1-NHAMAYABUÉ } \\
\text { (urbano-suburbano) }\end{array}$ & 9 & 28 & 32 & 26 & 24 & 16 & 25 & 32 \\
\hline $\begin{array}{l}\text { B2-MAFARINHA } \\
\text { (urbano-suburbano) }\end{array}$ & 9 & 23 & 25 & 21 & 17 & 15 & 15 & 23 \\
\hline \multirow[t]{2}{*}{$\begin{array}{l}\text { B3-THUNDANE } \\
\text { (periurbano) }\end{array}$} & 1 & - & 3 & 3 & 3 & 3 & 0 & 3 \\
\hline & & & & 50 & 44 & & & \\
\hline TOTAL & 19 & 51 & 60 & \multicolumn{2}{|c|}{94} & 34 & 40 & 58 \\
\hline
\end{tabular}

Fonte: Céline Veríssimo (2011). 
O Espaço Doméstico Exterior e o ecodesenvolvimento de cidades médias | 197

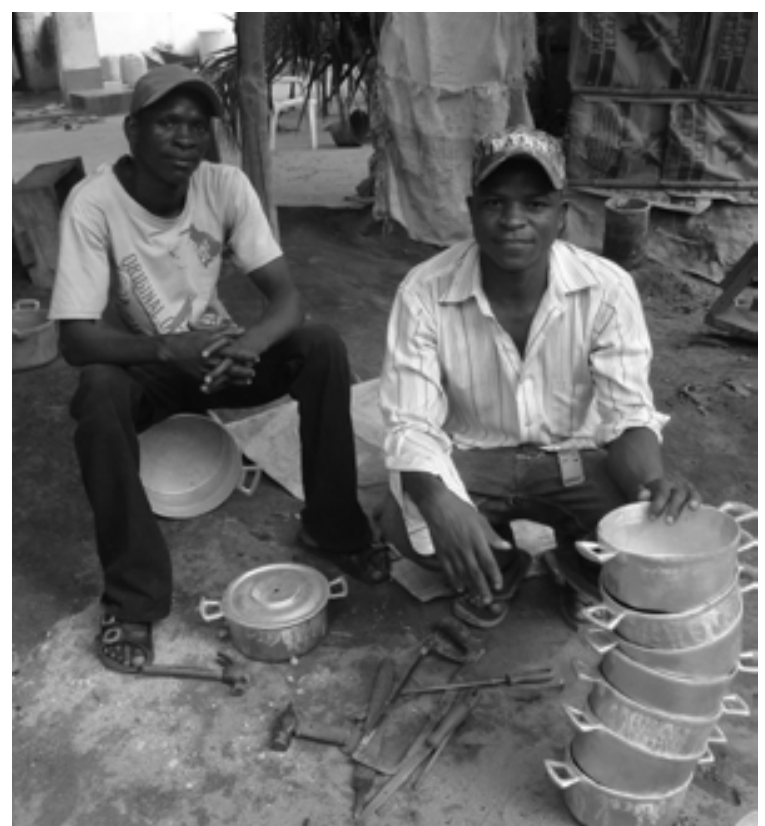

FIGURA 5 - Latoeiros (irmãos produtores e vendedores de panelas em liga de alumínio) no seu Espaço Exterior Doméstico no Bairro Mafarinha, Dondo

Fonte: Céline Veríssimo (2010).

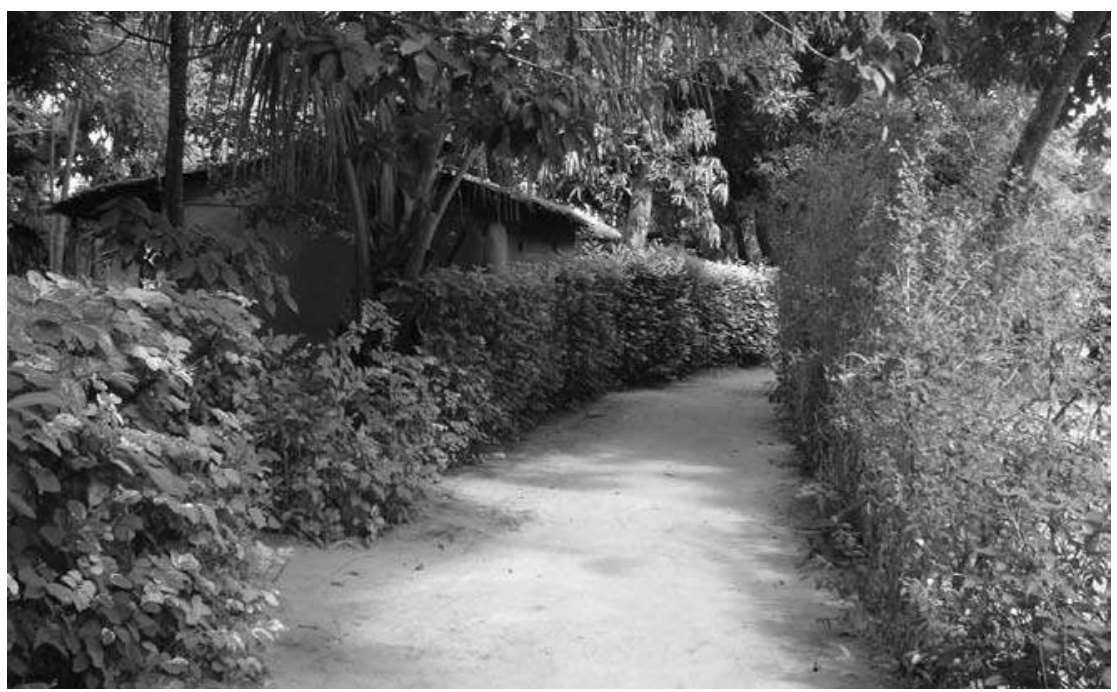

FIGURA 6 - Ambiente urbano agradável gerido coletivamente no Bairro Mafarinha, Dondo Fonte: Céline Veríssimo (2010) 


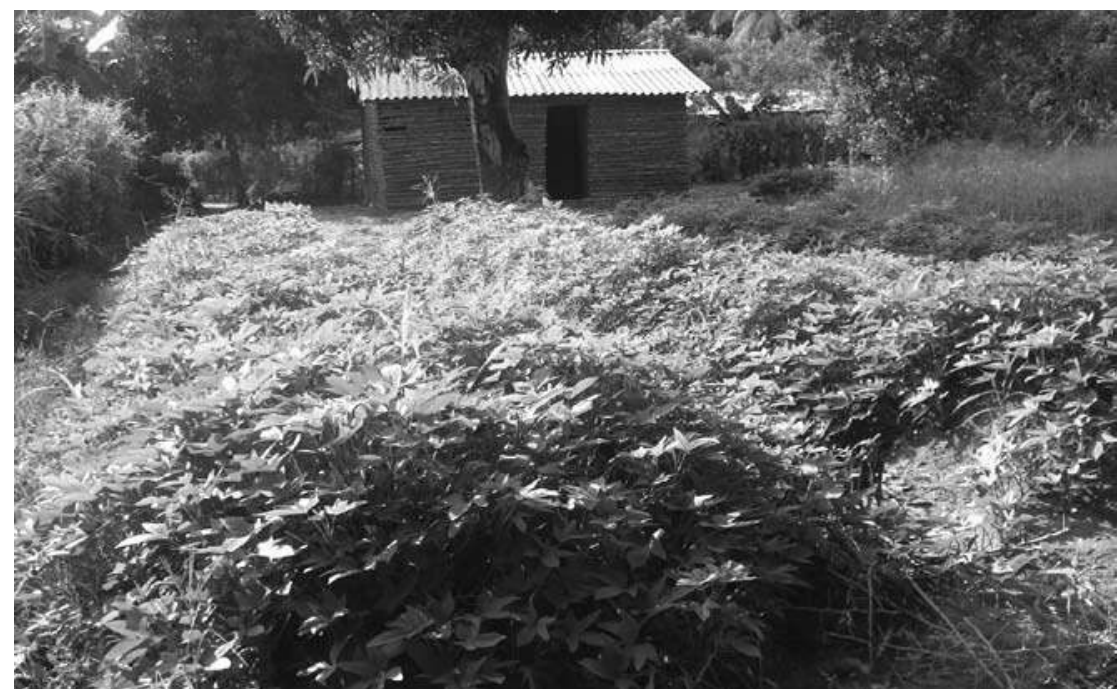

FIGURA 7 - Cultura agrícola doméstica (machamba) urbana no Bairro Nhamayabué, Dondo

Fonte: Céline Veríssimo (2010).

\section{Resiliência espacial, resistência e autossubsistência: uma herança histórica} Historicamente, a população de Moçambique enfrentou a opressão e a segregação socioespacial e reagiu de uma maneira que reforçou, ao invés de desmantelar, os seus valores tradicionais. Desde os tempos pré-coloniais, a estratégia da população para escapar à alteração ambiental e às perturbações da política externa foi reinventar a tradição, baseando-a nos princípios da resiliência, resistência e autossuficiência. A resistência espacial e a resiliência expressas através do desenvolvimento de povoações descentralizadas, envolvendo a apropriação da terra como espaço doméstico e a organização espontânea de EED e bairros, consistiam em estratégias para proteger a população de adversidades consecutivas. Durante a opressão colonial, eram usadas para combater a discriminação, o trabalho forçado e os impostos e, mais tarde, como rejeição da agenda de desenvolvimento nacional militarista da Frelimo no período pós-independência. Recentemente serviram ainda para deter o aumento intolerável dos preços dos alimentos e da energia, pelo governo de Guebuza. ${ }^{8}$ No seguimento desta tradição de insurreição espacial da população e da explosão urbana da pós-independência, a cidade moçambicana ganhou mais substância e autonomia, o que lhe permitiu criar condições para a sobrevivência urbana e maior bem-estar em tempos de dificuldade.

\footnotetext{
${ }^{8}$ O 1-2 de setembro de 2010 'Maputo Food Riots'.
} 
O futuro da urbanização de Moçambique beneficiaria com o conhecimento e o reforço do potencial desenvolvido pelos habitantes dos bairros informais, que se provou mais útil e eficaz para efetivamente resolver as necessidades reais da população e ajudar a lidar com os desafios urbanos do que as abordagens de planeamento neocolonial. O modo como o EED molda uma forma urbana ruralizada desafia as abordagens 'de cima para baixo', importadas do urbanismo pós-moderno, às relações entre a expansão informal da cidade, a população urbana em crescimento e a deterioração do ambiente, que, em vez de melhorarem a vida urbana, potenciam a desigualdade social, a segregação espacial e a pobreza urbana. Dado que a grande maioria da população urbana depende do EED para rendimentos estáveis, sugiro que, através da consciencialização, do reconhecimento e de processos colaborativos, a expansão urbana espontânea contribui não só para uma forma legítima e mais sustentada de desenvolvimento urbano, mas também para a mudança ambiental positiva através da qual a sociedade se recria a si própria ligada à natureza.

Aquilo que inicialmente é uma resposta social à crise torna-se intrinsecamente uma resposta também aos desafios ambientais, se o equilíbrio entre a humanidade e a natureza for precondição para a sobrevivência. Através da resiliência, o espaço urbano descentralizado não só tem capacidade de retomar o equilíbrio perante choques, como também pode reinventar um novo estado de equilíbrio. As crises consecutivas em Moçambique tornaram os sistemas sociais bastante resilientes ao nível de sobrevivência básica. Contudo, durante este processo deram um passo ainda mais à frente, que ultrapassa a simples sobrevivência, e criaram uma nova forma dinâmica de equilíbrio, pronta a responder aos desafios presentes e futuros, movendo-se gradualmente em direção a um novo género de equilíbrio na relação entre a humanidade e a natureza.

\section{Problemas subjacentes à divisão ecocêntrica-antropocêntrica}

As verdadeiras causas da degradação ambiental, precariedade de recursos, mudança climática, pobreza, fome mundial e terrorismo não residem no facto de o planeta ter demasiada gente concentrada no Sul e as capacidades limitadas da Terra. Os fatores económicos e políticos que produzem a desigual distribuição de recursos e o acesso limitado aos direitos da democracia, entre muitos outros resultados, são gerados pelo modelo económico de capitalismo que escravizou a civilização humana. Definitivamente não se trata de uma questão de população, visto que se toda a gente organizasse o seu próprio trabalho e criasse bem-estar num modo de vida ecologicamente harmonioso em agrocidades descentralizadas, estaria garantida a 
continuação segura de uma civilização mais democrática e a regeneração da vida natural. Aquilo que em tempos foi visto como algo radical e utópico encontra agora um espaço de manobra. As abordagens de desenvolvimento sustentável convencional ignoram a exploração de classes e a desigualdade social e falham em encarar os problemas que decorrem da relação entre humanidade e natureza nas sociedades das nações do Norte e do Sul - as discrepâncias entre centro e periferia. A sociedade, a natureza e o capitalismo são por isso intrinsecamente incompatíveis ${ }^{9}$ e, se o capitalismo sobrevive, os esforços para travar as crises sociais e ambientais continuarão a ter um impacto muito limitado, enquanto aumenta o fosso entre a natureza e a sociedade.

\section{Orientações de pesquisa e objetivos}

O modelo sugerido de ecodesenvolvimento para as cidades médias não pode ser baseado numa fórmula ou num projeto, o que seria contraditório. O modelo de agrocidade baseia-se, em vez disso, na experiência obtida a partir da realidade, que sugere que uma continuação democrática e segura dos sistemas de vida na Terra dependem de uma transição para o ecossocialismo. Assim, a organização espontânea do espaço urbano através do Espaço Exterior Doméstico como o principal pilar para a expansão dos bairros informais nas cidades médias em Moçambique é vista aqui não só como uma resposta resiliente dos sistemas sociais, que enfrentam contínuas dificuldades devido a mudanças políticas e ambientais, mas em particular como um indicador de uma ordem social emergente, que visa o regresso a uma relação simbiótica entre os assentamentos humanos e a natureza. A agrocidade apresenta-se como um modelo concetual para um desenvolvimento urbano sustentado, que pode ser considerado no contexto de cidades médias espontâneas e é baseado num exemplo existente - o caso do Município do Dondo, Moçambique. Dado que este artigo também tem o objetivo de destacar o papel crucial das agências e da mudança política para o reconhecimento do significado do trabalho colaborativo com a população como meio de acabar com o atual isolamento e segregação, sugiro que a resiliência possa ser alargada a um nível institucional como um modo efetivo de enfrentar os desafios urbanos.

\footnotetext{
${ }_{9}$ O capitalismo produz dinheiro para produtos através do trabalho, que explora os recursos humanos criando entropia social enquanto usa energia (entropia negativa) e produz desperdícios (entropia elevada) em constantes círculos de feedback (Biel, 2010).
} 


\section{Habitat humano e natureza}

A cidade é por um lado um produto espacial da civilização e por outro um produto espacial da natureza, no sentido em que a humanidade faz parte dos processos da natureza. Afastando-se do argumento convencional de que o crescimento da população e a dispersão urbana são fonte de múltiplos problemas, a noção de 'cidade' aqui adotada enfatiza uma conexão social simbiótica com a natureza. Isto é considerado como um potencial inerente e poderoso para se tornar parte da solução para os problemas do mundo no século XXI (Lovelock, 1979), que não foi totalmente explorado. A natureza descentralizada do estudo de caso fornece provas de que a cidade informal pode desempenhar um papel essencial no desenvolvimento ecológico através da contribuição para o crescimento económico local, de melhorias ambientais, identidade social reforçada e autoestima individual, atenuação da pobreza urbana, ecossistemas e conservação dos recursos, entre outros fatores. As práticas coletivas descentralizadas da paisagem urbana de Moçambique provam que a própria cidade é central na criação de oportunidades para o desenvolvimento humano e para a regeneração ambiental, com vantagens para além dos limites do município. Como resultado, a cidade que se expande pela autorregeneração do seu próprio ecossistema natural em crescimento não só melhora a qualidade do ambiente urbano, como também reduz a pressão humana sobre os recursos naturais nas áreas periurbanas. Desafiando as suposições geralmente negativas associadas ao desenvolvimento urbano, o baixo insumo do ambiente construído das agrocidades, o sistema agrícola e o padrão de consumo permitem que a cidade contribua para a diminuição do aquecimento global.

\section{O metabolismo da agrocidade}

O Espaço Exterior Doméstico é aqui considerado como o bloco de construção ou a unidade celular de um todo mais vasto, a agrocidade, cuja definição é explorada ao nível dos detalhes de um sistema operativo mais amplo, das suas dinâmicas e implicações globais (socioculturais, económicas, ecológicas e institucionais) (ver Figura 8). A célula é resiliente e incorpora o conhecimento moderno e tradicional, fornecendo as bases para a resiliência de todo o sistema - o habitat humano - face a choques.

Historicamente, o habitat humano, como espaço para a produção e concentração humana, tem sido encarado como fonte de conflito, atingindo o seu pico durante o capitalismo. Em contraste, este caso demonstra que são possíveis outras formas de assentamentos humanos e de produção - o uso do EED, o processo produtivo e a auto-organização dos bairros são, eles próprios, expressões da troca material-energia na relação entre a sociedade 
e a natureza. A agrocidade dissipa a diferenciação social e as relações de poder, promovendo a inclusão através de uma rede de trabalho colaborativo. Analiso aqui o metabolismo da agrocidade como um sistema autorregulador (Girardet, 1996), separado e derivado do modelo urbano pós-modernista (colonial e neocolonial) tecnocrático, relacionado com processos mais amplos de mudança histórica política e económica.

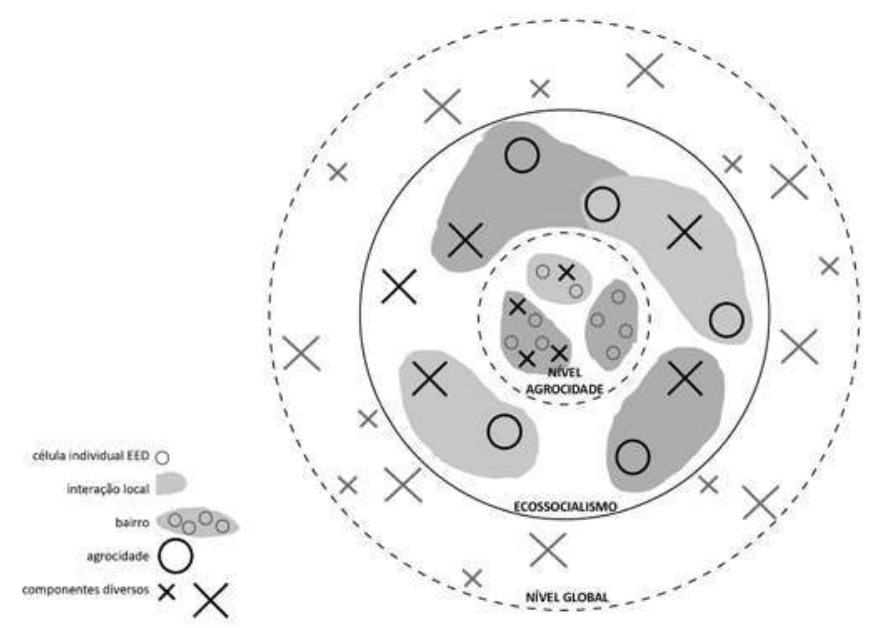

FIGURA 8 - O metabolismo da agrocidade: a interação entre unidades de espaço exterior doméstico formando bairros e agrocidades a nível local e comportamentos emergentes a nível global

Fonte: Céline Veríssimo (2011).

\section{Questão de investigação e hipótese}

Considerando a atual crise global como oportunidade de mudança de paradigma civilizacional, este artigo investiga o papel simbiótico intrínseco à relação entre o habitat humano e a natureza,${ }^{10}$ questionando: Como pode ser conceptualizado um novo paradigma de desenvolvimento urbano, capaz de expandir livremente e em equilíbrio com um desenvolvimento mais democrático da civilização bumana e a regeneração dos ecossistemas do planeta? A hipótese proposta explica que: existe uma estrutura urbana informal emergente (auto-organizada), cuja célula individual básica ou unidade é o agregado

$\overline{10}$ Conceito de 'humanidade' como parte da natureza e de 'cidade' como o habitat onde os humanos residem como parte dos sistemas de vida da natureza. 
familiar centrado no Espaço Exterior Doméstico individual. Este sistema é sustentável (em termos de diferentes indicadores: ambientais, económicos, socioculturais, etc.) tanto ao nível micro da unidade individual, como ao nivel macro do conjunto mais alargado (os bairros das cidades médias). Este fenómeno, aqui estudado aos niveis micro e macro, remete claramente os mesmos temas que o paradigma do ecodesenvolvimento aborda. Explorando a convergência entre, por um lado, uma teoria de ecodesenvolvimento libertada das suas ilusões modernistas (que entendia planeamento racional como antítese da ordem emergente), mas retendo a sua válida orientação normativa e, por outro lado, a experiência do desenvolvimento urbano espontâneo auto-organizado como se encontrou no Dondo, conduz à noção de agrocidade.

A primeira parte da hipótese é relativa ao metabolismo urbano em que a célula individual - o Espaço Exterior Doméstico - é bloco de construção do metabolismo mais vasto - a cidade informal ou seja, o habitat humano. Da perspetiva de teoria da complexidade, as caraterísticas do todo como um sistema dinâmico aberto não podem derivar inteiramente da compreensão da unidade individual por si só, visto que a célula não é autónoma, mas interage dinamicamente com as suas partes. Por isso, compreender o modelo completo de agrocidade depende da compreensão da relação dinâmica entre a célula - a família centrada no EED - e o sistema mais amplo - os bairros comunitários da agrocidade.

A segunda parte da hipótese incide na sustentabilidade do sistema da agrocidade através da resiliência das células EED, unificadas pelo conhecimento cultural. Estes são sustentáveis porque as famílias organizam o seu sustento a partir dos EED de um modo altamente flexível, capaz de sobreviver ao nível da agrocidade, combinando o conhecimento tradicional e contemporâneo perante a crise. Por esta razão, sem sustentabilidade cultural, a sustentabilidade a qualquer outro nível é muito improvável.

A terceira parte da hipótese diz respeito à evidência do estudo de caso, que se adapta ao paradigma do ecodesenvolvimento, mostrando como este se concretiza na realidade, ultrapassando a teoria e alcançando um modelo de ecodesenvolvimento para cidades médias, baseando-se no e reinterpretando o ecossocialismo. A parte final da hipótese refere-se ao aspeto normativo do modelo de agrocidade, argumentando que devia ser integrado no planeamento de desenvolvimento urbano e legislativo e não numa convencional e modernista abordagem de 'cima para baixo', mas num plano de 'baixo-para-cima' que valoriza e reforça práticas locais inovadoras. O papel do Estado e das agências económicas locais é importante, não para contradizer, mas para reconhecer a importância e a legitimidade da articulação dos processos colaborativos com a ordem espontânea emergente, 
enquanto passo necessário e legítimo na direção de um planeamento de desenvolvimento mutuamente vantajoso.

\section{Conceitos-chave}

\section{Espaço Exterior Doméstico}

Este é um espaço multifacetado que se refere ao espaço externo em redor da construção da casa e, no caso de Moçambique, é onde as atividades diárias da família têm lugar, envolvendo fortes funções sociais e produtivas, bem como reprodutivas (ver Figura 9). Para compreender por que razão esta pesquisa utiliza a terminologia de EED em vez do ocidental 'pátio/quintal', 'recinto' ou 'talhão' é necessário entender primeiro a noção de 'casa' e 'lar' dentro do contexto cultural de Moçambique. Os termos 'casa', 'lar' e 'assentamento' têm exatamente o mesmo significado e são chamados muti em ronga e changana, as línguas mais faladas. O muti pode portanto ser descrito como um aglomerado doméstico, ou um casario, que aloja uma família muito extensa, com árvores plantadas e várias casas ou palhotas e geralmente rodeado por uma área cultivada. Já não se encontram mutis que integrem várias gerações de membros da família, a não ser em áreas mais remotas. Nas áreas rurais, aquilo que no passado constituía uma mistura de várias casas consiste agora em três a cinco casas. Enquanto as casas construídas servem para dormir, armazenar e proteger da chuva, o Espaço Exterior Doméstico sem construções é o centro da vida doméstica e social. Os limites do Espaço Exterior Doméstico são muito ambíguos, como o são as esferas privadas e públicas do espaço doméstico. O caráter de urbanidade doméstica inerente ao EED facilita não só a emergência de negócios domésticos, mas sobretudo a manutenção de redes sociais importantes. Mais importante é o conceito herdado de organização do espaço de acordo com funções e componentes, o significado coletivo de habitação, os materiais de construção e tecnologia e o modo como estes evoluíram para responder às novas condições ambientais, políticas, económicas e sociais.

Definido aqui como a evolução do muti tradicional numa urbanização atual espontânea, o Espaço Exterior Doméstico foi adaptado e melhorado para resistir à opressão e adversidade, numa revolta silenciosa para estabelecer uma segurança coletiva. Moldando as cidades moçambicanas, o Espaço Exterior Doméstico é resiliente, pois tem condições para adaptar o espaço doméstico a novas (agro e não agro) funções produtivas como estratégia para garantir a subsistência (alimentação e rendimento) e produz um microclima no bairro confortável e limpo (sombra e ar fresco). Com base em princípios de diversidade e flexibilidade, culturas mistas intensivas são combinadas com gado, serviços e comércio no EED, adaptando a produção de alimentos 


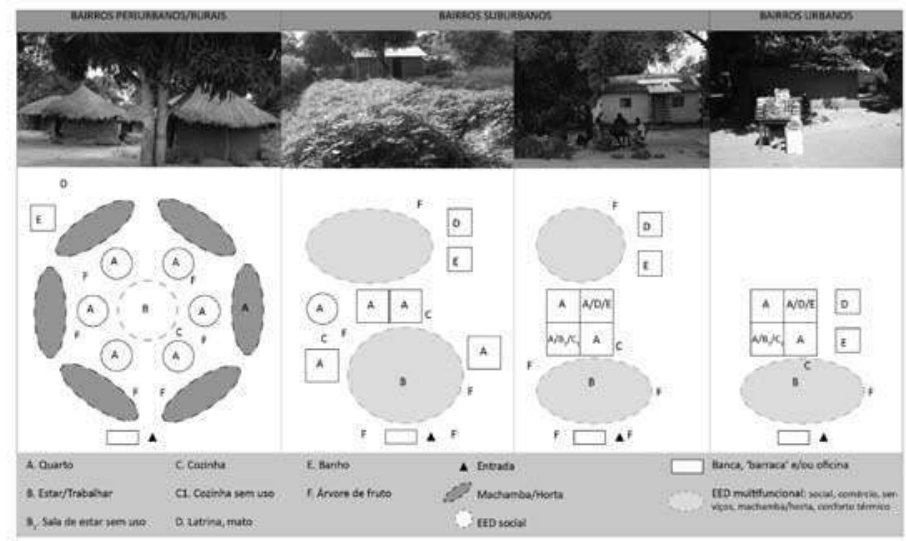

FIGURA 9 - Transformação do espaço exterior doméstico e subsistência auto-organizada nos bairros espontâneos do Dondo

Fonte: Céline Veríssimo (2009).

domésticos às mudanças de clima e das reformas políticas e económicas, lidando com recursos escassos e gerando também rendimento. Os limites imprecisos entre as relações de parentesco alargadas que ocorrem, para além do nível familiar no EED, ao nível da comunidade de bairro, alargam-se à cidade, antecipando o potencial do EED para a organização coletiva.

\section{$A$ agrocidade}

A urbanização atual em Moçambique é dualística - encerra o conflito entre cidades formais e informais - e resulta de dinâmicas contínuas da fragmentação socioespacial e da diferenciação alimentada pelos regimes políticos antidemocráticos. Apesar de o bairro informal ser o local onde a maioria dos moçambicanos urbanos vivem e trabalham e constituir o centro negligenciado mas legítimo da dinâmica da cidade, existe uma permeabilidade entre a 'cidade de cimento' formal e os bairros espontâneos, dados os fluxos de pessoas e produtos que circulam entre ambos. A agrocidade é uma revalorização da urbanização moçambicana baseada nas práticas descentralizadas existentes ao nível popular, tal como se encontra nos bairros da cidade do Dondo, cuja definição tem uma base positiva (no que toca ao conhecimento das suas características atuais) e uma base normativa (no que se refere a estabelecer um padrão ideal baseado nas práticas existentes). Tal como o EED público e as esferas privadas são ambíguos, a agrocidade rural e as dimensões urbanas são imprecisas, 
pois as áreas rurais são espaços 'naturalmente' transformados pela presença humana, enquanto nas cidades essa presença se impõe reproduzindo a natureza como o seu próprio habitat e tipo de residência.

A agrocidade é uma forma ruralizada de urbanização, ou um sistema urbano semirrural com um desempenho ecológico intrinsecamente positivo que também é capaz de reduzir a degradação ambiental, otimizando e maximizando o seu bloco de construção, o EED. Enquanto a Cidade Jardim de Howard, rigidamente planeada, é racionalizada e deliberadamente procurada (Howard, 1902), tal como em outras ecocidades, ${ }^{11}$ a agrocidade é um sistema espontâneo autorregulado naturalmente orgânico, que mantém o ritmo dos ciclos de vida da natureza na procura de sobrevivência, bem-estar e prolongamento da vida. Ao longo do seu processo dinâmico de evolução através do tempo, a agrocidade tem funcionado e resistido aos impactos das mudanças políticas, económicas e ambientais. Uma grande diferença ente a cidade dualística convencional e a agrocidade é a alteração das polaridades - a cidade formal torna-se estrategicamente periférica com funções secundárias, enquanto os bairros informais são reconhecidos como o centro genuíno do sistema da cidade, onde flui a energia e onde se centralizam as dinâmicas das relações culturais, socioeconómicas e ecológicas. Os componentes-chave do metabolismo circular da agrocidade, necessários para criar os seus próprios sistemas de controlo de modo a manter o seu equilíbrio ecológico, são a intensificação da produção, o crescimento da população, a reprodução dos alimentos locais, recursos e energia através de comunidades auto-organizadas e autónomas, independentes da economia global e dos imperativos do Estado. Na medida em que permite espaço para uma colaboração com as agências oficiais que mantenham a estrutura interior social e a organização intactas, a fim de criar resultados mutuamente benéficos, ${ }^{12}$ a agrocidade demonstra que o desenvolvimento urbano em equilíbrio com a natureza é social, política e economicamente possível.

\section{Resiliência espacial}

A resiliência espacial pode ser aqui definida como uma análise crítica da transformação espacial que apoia os sistemas sociais e naturais resilientes que surgiram como reação natural a uma adversidade. A capacidade inerente

\footnotetext{
${ }^{11}$ As ecocidades contemporâneas como Madar, Tangshan Caofeidan, Tianjin, entre outras. "De uma perspetiva puramente ecológica, as cabanas e os seus residentes são um bom exemplo do novo metabolismo urbano verde. Apesar das falhas sanitárias e de segurança, têm muitas vezes uma vibração social e os sistemas ecológicos que se perdem na maioria das cidades planificadas" (Pearse, 2006: 3).

${ }_{12}$ Nomeadamente gestão de resíduos, distribuição de água, produção local de alimentos, gestão de recursos naturais.
} 
ao EED para a diversificação espacial e a flexibilidade, ou seja resiliência espacial, que surgiu espontaneamente da adaptação e recuperação em relação às mudanças autoritárias da política e da economia e das crises ambientais, melhora com efeito os níveis de resiliência do sistema da agrocidade. O sistema da agrocidade precisa de ser resiliente para se autorregenerar após adversidades e restabelecer o equilíbrio inato da humanidade com a natureza, como uma 'memória ecológica. ${ }^{13} \mathrm{~A}$ natureza diversificada do Espaço Exterior Doméstico, que inclui localização, dispersão, isolamento, concentração, inter-relação e dimensões privadas/ /públicas ambíguas, é também a concretização da resistência popular à marginalização. A resiliência espacial do EED e da agrocidade destaca os aspetos espaciais que estão na base dos sistemas sociais e de vida natural, porque tem como objetivo preservar a relação humana simbiótica com a natureza, que é fundamental para assegurar a base de recursos para a subsistência e a regeneração da vida natural.

Dado o histórico moçambicano de autossubsistência, resiliência espacial e resistência silenciosa, foi possível uma revolução ecossocialista que já teve lugar - através da apropriação espontânea da terra, autogestão do ambiente e livre (não planeada) utilização do espaço para a segurança coletiva, necessidades de subsistência, redes sociais vitais e preservação da base de recursos naturais. A resiliência espacial e social profundamente enraizada na sociedade civil, subjacente à ajuda mútua e às relações de reciprocidade, pode gerar não só oportunidades e cenários férteis para um futuro ecodesenvolvimento de cidades médias, mas também trazer conhecimentos para a análise da relação entre sociedade e natureza, baseada na sua dinâmica espacial.

\section{Conclusão}

O modo como o desenvolvimento sustentável (DS) evolui degenerando de alguma maneira para interpretações múltiplas tendenciosas está diretamente associado com o problema de investigação. Este artigo critica o DS no que toca à(s) sua(s) tentativa(s) falhada(s) em orientar a relação da humanidade para a natureza, argumentando que isso pode ter acontecido porque este tende a acomodar-se ao paradigma do desenvolvimento do capitalismo. O modelo de DS só pode ter sucesso se existir uma mudança de paradigma na economia política mundial que reconheça a importância das condições

\footnotetext{
13 'Memória ecológica' é a composição e distribuição de organismos e as suas interações no espaço e no tempo, e inclui a biografia das experiências com as flutuações ambientais. A memória reflete a fundação histórica da resiliência dos ecossistemas e é um componente chave da resiliência espacial (Magnus Nystron e Carl Folke, 2001: 411).
} 
ambientais naturais para a recuperação dos sistemas locais emergentes. ${ }^{14}$ Isto porque a sua natureza intrinsecamente resiliente provou o seu êxito em dar-lhes meio de adaptação face a adversidades no passado, demonstrando que têm boas hipóteses de atingir a autonomia no futuro, dados os desafios da atual crise mundial. Já existem muitas estratégias de desenvolvimento, tal como estratégias de devolução, de subsidiariedade e participativas, nas quais o aparelho estatal reconhece gradualmente e não subverte os sistemas emergentes, embora em contradição com o modo capitalista de produção, na mira de se libertar da dependência dos programas de ajuda. Isto pode em parte constituir uma vantagem para os sistemas emergentes, visto que a cooperação para o desenvolvimento não traz apenas benefícios, devido à corrupção e ao controlo externo dissimulado sob a economia política das nações em desenvolvimento (Hanlon, 2010). É possível que os programas de desenvolvimento colaborativo sejam menos pesados do que os programas de cooperação para o desenvolvimento, uma vez que os fundos de ajuda internacional são menores e provavelmente mais eficientes no terreno.

O presente artigo questiona o modo como o crescimento urbano e os desafios urbanos nas cidades do mundo em desenvolvimento são abordados, usando métodos importados de planeamento, como se existisse um urbanismo universal. Tais métodos podem mostrar-se eficazes no seu contexto original, mas são inapropriados para providenciar o acesso igualitário a infraestruturas urbanas e serviços a uma população urbana no contexto de cidades do mundo em desenvolvimento. De acordo com as evidências do estudo de caso do Dondo, os modelos estrangeiros aumentam a pobreza urbana e a segregação socioespacial, têm um impacto no ambiente e intensificam a urbanização dualística. Os resultados sugerem que a urbanização emergente em Moçambique precisa de ser reconhecida como o núcleo legítimo no que se refere aos seus níveis culturais, económicos, políticos e ecológicos, para que os obstáculos criados pelas conceções neocoloniais equivocadas possam ser superadas e a desigualdade socioespacial, a fragmentação espacial, os desafios urbanos e a degradação dos recursos periurbanos possam ser abordados de maneira mais eficiente.

Os resultados de investigação destacam que a utilização atual do espaço doméstico auto-organizado pode dar uma forte contribuição para assegurar meios de subsistência, configurando uma forma urbana semirrural e ecológica e reduzindo a pressão urbana sobre o ambiente natural. $\mathrm{O}$ facto de

\footnotetext{
${ }^{14} \mathrm{O}$ reconhecimento dos sistemas emergentes já existe no sistema capitalista, mas funciona num modo explorativo. Enfrentando a crise, o neoliberalismo movimenta-se em direção à auto-organização para se tornar mais autossuficiente e menos vulnerável a fatores externos, como o controlo estatal e sistemas de tecnologia da informação.
} 
que a vida urbana quotidiana e as estratégias de subsistência decorrem no Espaço Exterior Doméstico e não no interior de uma estrutura construída, demonstra que até nas cidades as pessoas podem recuperar a sua ligação humana inata com a natureza. No caso do Dondo, o cenário urbano é o novo terreno onde elas continuam a desenvolver esta relação com os processos naturais, devido à necessidade permanente de preservar a base de recursos naturais para assegurar a subsistência. Apesar de o conhecimento cultural poder tornar-se enganoso quando a vitalidade subjacente às suas origens e essência é substituída por conservadorismo estático e até um retrocesso, ele parece aqui ter preservado satisfatoriamente a relação simbiótica entre o habitat humano e a natureza.

A definição de agrocidade aqui apresentada critica simultaneamente o capitalismo moderno, pelas suas ações predatórias e obsoletas, e o socialismo, pelo centralismo democrático da Frelimo pós-independente, ambos ditados por fatores externos e internos. O ecodesenvolvimento envolve uma transição ecossocialista que aqui se considera já ter acontecido de maneira espontânea. Espera-se que isto suscite a consciência de quem decide e projeta e inspire outros a acreditar, como eu, que as cidades são mais do que lugares para a distribuição desigual de saúde, produção, pobreza, acumulação e resíduos. Embora as cidades sejam em geral conhecidas como fontes de mudanças ambientais, também têm condições para funcionar como força motriz no equilíbrio das relações entre a civilização humana e a natureza.

Tradução de Isabel Branco

\section{Referências bibliográficas}

Araújo, Manuel (1998), "Espaço e identidade", in Carlos Serra (org.), Identidade, Moçambicanidade, Moçambicanização. Maputo: Livraria Universitária, UEM, 161-171.

Araújo, Manuel (1999), "Cidade de Maputo. Espaços contrastantes: do urbano ao rural”, Finisterra, XXXIV(67-68), 175-190.

Araújo, Manuel (2002), "Ruralidades-urbanidades em Moçambique. Conceitos ou preconceitos?”, Revista da Faculdade de Letras, Geografia I série, XVII-XVIII, 2001-2002, 5-11.

Baía, Alexandre H. M. (2011), "Os meandros da urbanização em Moçambique", GEOUSP - Espaço e Tempo, 29 (especial 2011), 3-30.

Berberoglu, Berch (org.) (2012), Beyond the Global Capitalist Crisis: the World Economy in Transition. Surrey/Burlington: Ashgate Publishing. 
Biel, Robert (2010), The Urban Metabolism - part 1: circuits, natural and unnatural. London: Module ES4, Development Planning Unit, UCL.

Boughton, Duncan; Mather D.; Shirley, D.; Walker, T.; Cungara, B., Payongayong, E. (2006), Change in Rural Household Income Patterns in Mozambique, 1996-2002, and Implications for Agriculture's Contribution to Poverty Reduction. Maputo: Report 61E, Ministry of Agriculture and Michigan State University.

Brenner, Neil; Marcuse, P.; Mayer, M. (2009), "Cities for People, Not for Profit", City, Analysis of Urban Trends, Culture, Theory, Policy, Action, 13(2-3), 176-184.

Casal, Adolfo Yañez (1996), As aldeias comunais de Moçambique. Lisboa: Antropologia e Desenvolvimento, Ministério da Ciência e da Tecnologia, Instituto de Investigação Científica Tropical.

Costa, Ana Bénard da (2002), "Famílias na periferia de Maputo: Estratégias de sobrevivência e reprodução social”. Tese de Doutoramento em Estudos Africanos, Instituto Superior de Ciências do Trabalho e da Empresa, Lisboa. Versão eletrónica, consultada a 08.05.2013, em http://hdl.handle.net/10071/3044.

Costa, Ana Bénard da (2011), "Famílias de Maputo: processos de mobilidade e transformações urbana”, Revista Internacional em Lingua Portuguesa, 3. a Série, 23, 177-192.

Administração Distrital do Dondo (2006), Plano Estratégico de Desenvolvimento, Província de Sofala. Beira: Governo do Distrito do Dondo.

Downton, Paul (2009), Ecopolis: Architecture and Cities for a Changing Climate. Dordrecht: Springer.

Freund, Bill (2007), The African City: A History. New York: New Approaches to African History Series, Cambridge University Press.

Fuchs, Christian (2000), Concepts of Social Self-Organisation, INTAS Project 'Human Strategies in Complexity' Research Paper $N^{\circ} 4$, Institute of Design and Technology Assessment, Vienna University of Technology.

Fuchs, Christian (2003), “Co-operation and Self-Organization”, Triple C: Cognition, Communication, Co-operation, 1(1), 1-52.

Girardet, Herbert (1996), The Gaia Atlas of Cities: New Directions for Sustainable Urban Living. London: A Gaia Original, Gaia Books Limited.

Guedes, Amâncio d'Alpoim (1976), “The Caniços of Mozambique”, in Paul Oliver (org.), Shelter in Africa. London: Barrie and Jenkins, 200-209.

Hanlon, Joseph (2010), "Mozambique: The War Ended 17 Years Ago, But We Are Still Poor”, Conflict, Security \& Development, 10(1), 77-102.

Hardoy, Jorge E.; Satterthwaite, David (orgs.) (1986), Small and Intermediate Urban Centers: Their Role in Regional and National Development in the Third World. London: Hodder and Stoughton/IIED.

Howard, Ebenezer (1902), Garden Cities of To-morrow. London: Dodo Press.

INE (2007), Census 2007, Sistema Estatístico Nacional de Moçambique [www.ine.gov.mz]. 
INE (2012), Estatísticas do Distrito do Dondo. Maputo: Instituto Nacional de Estatística.

IPCC (2007), Climate Change 2007: Synthesis Report. Contribuição do Working Groups I, II and III to the Fourth Assessment Report of the Intergovernmental Panel on Climate Change, IPCC/WMO/UNEP.

Lovelock, James (1979), Gaia: A New Look at Life on Earth. Oxford: Popular Science, Oxford University Press.

Mabogunje, Akin L. (1994), "Urban Research Africa, Overview of Research Priorities in Africa”, in Richard Stern (org.), Urban Research in the Developing World, Vol. 2 - Africa. Toronto: Centre for urban and Community Studies, University of Toronto. Newit, Malyn (1997), A History of Mozambique. London: Hurst \& Company.

Nystron, Magnus; Folke, Carl (2001), "Spatial Resilience of Coral Reefs”, Ecosystems, 4(5), 411.

Pearse, Fred (2006), "Eco-cities special: Ecopolis now", NewScientist.com news service, 16 de junho.

Schmidt, Alfred (1971), The Concept of Nature in Marx. London: NLB.

Schultz, P. Wesley; Shriver, C.; Tabanico, J. J.; Khazian, A. M. (2004), "Implicit Connections with Nature”, Journal of Environmental Psychology, 24, 31-42.

Sheldon, Kathleen E. (1999), "Machambas in the City: Urban Women and Agricultural Work in Mozambique", Lusotopie, 121-140.

UN-HABITAT (2008), Mozambique: Urban Sector Profile. Nairobi: United Nations Human Settlements Programme.

UN-HABITAT (2012), World Urbanization Prospects: the 2011 Revision Population Database. Nairobi: United Nations Population Division.

Veríssimo, Céline (2010), "Dondo Fieldwork Report”. Development Planning Unit, University College London (junho). 
